\title{
Observing entrainment mixing, photochemical ozone production, and regional methane emissions by aircraft using a simple mixed-layer framework
}

\author{
Justin F. Trousdell ${ }^{1}$, Stephen A. Conley ${ }^{1,2}$, Andy Post ${ }^{1,3}$, and Ian C. Faloona ${ }^{1}$ \\ ${ }^{1}$ Department of Land, Air, and Water Resources, University of California, Davis, California, USA \\ ${ }^{2}$ Scientific Aviation, Inc., Boulder, Colorado, USA \\ 3 the California Air Resources Board, Sacramento, California, USA \\ Correspondence to: Ian C. Faloona (icfaloona@ucdavis.edu)
}

Received: 16 July 2016 - Published in Atmos. Chem. Phys. Discuss.: 29 July 2016

Revised: 28 October 2016 - Accepted: 28 October 2016 - Published: 15 December 2016

\begin{abstract}
In situ flight data from two distinct campaigns during winter and summer seasons in the San Joaquin Valley (SJV) of California are used to calculate boundary-layer entrainment rates, ozone photochemical production rates, and regional methane emissions. Flights near Fresno, California, in January and February 2013 were conducted in concert with the NASA DISCOVER-AQ project. The second campaign (ArvinO3), consisting of 11 days of flights spanning June through September 2013 and 2014, focused on the southern end of the SJV between Bakersfield and the small town of Arvin, California - a region notorious for frequent violations of ozone air quality standards. Entrainment velocities, the parameterized rates at which free tropospheric air is incorporated into the atmospheric boundary layer (ABL), are estimated from a detailed budget of the inversion base height. During the winter campaign near Fresno, we find an average midday entrainment velocity of $1.5 \mathrm{~cm} \mathrm{~s}^{-1}$, and a maximum of $2.4 \mathrm{~cm} \mathrm{~s}^{-1}$. The entrainment velocities derived during the summer months near Bakersfield averaged $3 \mathrm{~cm} \mathrm{~s}^{-1}$ (ranging from 0.9 to $6.5 \mathrm{~cm} \mathrm{~s}^{-1}$ ), consistent with stronger surface heating in the summer months. Using published data on boundary-layer heights we find that entrainment rates across the Central Valley of California have a bimodal annual distribution peaking in spring and fall when the lower tropospheric stability (LTS) is changing most rapidly.

Applying the entrainment velocities to a simple mixedlayer model of three other scalars $\left(\mathrm{O}_{3}, \mathrm{CH}_{4}\right.$, and $\left.\mathrm{H}_{2} \mathrm{O}\right)$, we solve for ozone photochemical production rates and find wintertime ozone production $\left(2.8 \pm 0.7 \mathrm{ppbh}^{-1}\right)$ to
\end{abstract}

be about one-third as large as in the summer months $\left(8.2 \pm 3.1 \mathrm{ppbh}^{-1}\right)$. Moreover, the summertime ozone production rates observed above Bakersfield-Arvin exhibit an inverse relationship to a proxy for the volatile organic compound (VOC) : $\mathrm{NO}_{x}$ ratio (aircraft $\left[\mathrm{CH}_{4}\right]$ divided by surface $\left.\left[\mathrm{NO}_{2}\right]\right)$, consistent with a $\mathrm{NO}_{x}$-limited photochemical environment. A similar budget closure approach is used to derive the regional emissions of methane, yielding $100( \pm 100) \mathrm{Gg} \mathrm{yr}^{-1}$ for the winter near Fresno and 170 $( \pm 125) \mathrm{Gg} \mathrm{yr}^{-1}$ in the summer around Bakersfield. These estimates are 3.6 and 2.4 times larger, respectively, than current state inventories suggest. Finally, by performing a boundarylayer budget for water vapor, surface evapotranspiration rates appear to be consistently $\sim 55 \%$ of the reference values reported by the California Irrigation Management Information System (CIMIS) for nearby weather stations.

\section{Introduction}

During the daytime over the continents, when near-surface ozone $\left(\mathrm{O}_{3}\right)$ usually reaches its peak, convective thermals generated by surface heating rise and penetrate into the stable layer that demarcates the interface between the turbulent atmospheric boundary layer (ABL) and the laminar (nonturbulent) free troposphere (FT) above it. The continuous action of these thermals penetrating into the laminar-overlying air and falling back into the boundary layer gives rise to an irreversible mixing process that causes the layer to grow up 
through the mid-morning to afternoon, diluting the air in the ABL with that from the FT. The overall process is referred to as entrainment, and when the two layers contain different amounts of any scalar quantity (e.g., ozone concentration, water vapor, enthalpy), this mixing tends to be a significant contributor to the ABL budget of the scalar (Vilà-Guerau de Arellano et al., 2011; Lehning et al., 1998), and therefore vital to predicting and interpreting its abundance at the surface.

Typically entrainment is not treated explicitly in chemical transport models because the scales of motion, taking place predominantly within the ABL capping inversion, are suppressed in vertical extent due to the thermodynamic stability of this layer. Consequently the mixing tends to be sub-grid in nature and requires some form of parameterization. Many aircraft measurements of this parameter have been attempted using the tracer method (Nichols, 1984; Kawa and Pearson, 1989a; Faloona et al., 2005; Karl et al., 2013) wherein a trace gas flux is divided by the jump in its concentration across the inversion; however this requires the use of eddy correlation to measure the turbulent fluxes near the top of the ABL. Because the aircraft used in the present study, operated by Scientific Aviation, Inc., does not currently have the capability to measure vertical wind speeds, we use here instead measurements of the ABL growth rate and a budget of the inversion base height (Wood and Bretherton, 2004; Faloona et al., 2005; Albrecht et al., 2016) to infer the entrainment rate, based on the fact that $\mathrm{ABL}$ growth is driven in large part by entrainment.

Another meteorological process that can strongly influence surface concentrations is horizontal advection, and owing to the intricacies of the surface wind field in complex terrain and heterogeneity of surface sources of trace gases, this term has traditionally been difficult to account for in groundbased air pollution studies. Past measurements of DMS, $\mathrm{SO}_{2}$, and $\mathrm{O}_{3}$ budgets carried out over the (presumed homogenous) ocean indicate that while on average the advection term is not large, it can be dominant on any given day, and so must be considered when looking at individual episodes (Conley et al., 2009, 2011; Faloona et al., 2010). The central goal of the work presented here is to show how, by way of targeted small-scale airborne campaigns, it is possible to probe the regional ABL vertically and horizontally to calculate entrainment rates and mesoscale advection and thereby shed light on all of the processes that change the concentrations of trace gases in the boundary layer throughout the day. This methodology thereby reveals the quantitative origins of chemical concentrations, measured in near-surface air by comparing direct observations of all but one of the leading terms of the scalar budget equation, and infers the unknown term as a residual.

Outlined in the seminal work of Lenschow et al. (1981) are original applications of the scalar budgeting techniques used by Warner and Telford (1965) and Lenschow (1970) to help validate the newly developing technique of eddy covariance for measuring sensible heat fluxes by aircraft. Lenschow et al. (1981) go on to describe the effectiveness of welldesigned aircraft ABL studies in determining the net source or sink (in their case for ozone) given the careful measurement of the other dynamically controlled terms. The technique can be generalized to any scalar budget (i.e., ozone, water vapor, $\mathrm{DMS}, \mathrm{SO}_{2}$, and isoprene) to enable the calculation of important residuals including source or sink terms for non-conserved species (Kawa and Pearson, 1989b; Bandy et al., 2011; Conley et al., 2009; Faloona et al., 2010; Wolfe et al., 2015). In the process of quantifying the individual terms of the budget equations, their relative importance can be weighted to provide a better understanding of the leading causes and factors affecting surface concentrations.

A contemporary challenge for air quality monitoring, in the age of increasing sophistication of remote sensing from space, is correlating surface concentrations of key trace gases $\left(\mathrm{NO}_{x}, \mathrm{O}_{3}\right.$, etc.) with column measurements from satellites. Many air pollutants of interest are concentrated predominantly in the boundary layer, where the main sources are often located; thus there is a strong need for understanding the diurnal behavior of the mixed layer. One possible way to improve the correlation between surface and column concentrations is by understanding its connection to ABL height, and also the role of ABL mixing with the FT (entrainment). The depth of the ABL directly affects the concentration of tracers (i.e., surface levels), as they will be diluted and mixed throughout it. Recent studies in California by Al-Saadi et al. (2008) suggest that lidar measurements of ABL height can normalize column observations of AOD (aerosol optical depth) to greatly improve correlations to surface $\mathrm{PM}_{2.5}$ (particulate matter up to $2.5 \mu \mathrm{m}$ in size). Improving the inference of surface concentrations from satellite data is among the chief scientific goals of the NASA experiment DISCOVERAQ (deriving information on surface conditions from column and vertically resolved observations relevant to air quality). Seven of our flights were conducted during the California campaign of DISCOVER-AQ, in an effort to support their scientific mission. DISCOVER-AQ sought to use concurrent integrated observations to meet this goal, and among them was the University of California, Davis (UC Davis), in situ aircraft measurements of trace gas and thermodynamic budgets to better understand the diurnal behavior of the wintertime boundary layer in the San Joaquin Valley.

The San Joaquin Valley (SJV) of California is well known for its ozone (summer) and $\mathrm{PM}_{2.5}$ (winter) air quality challenges. As of 2013 the valley is a non-attainment site for the state standard and the federal $8 \mathrm{~h}$ standard for $\mathrm{O}_{3}$, a status that is likely to only become aggravated by the recent reduction in the federal $8 \mathrm{~h}$ standard to $70 \mathrm{ppbv}$ (US EPA). Additionally, the majority of the SJV, especially the southern portion, is designated non-attainment for $\mathrm{PM}_{2.5}$ for state and federal standards (California Air Resources Board, CARB) as of 2013. In winter the $\mathrm{SJV}$ is plagued by $\mathrm{PM}_{2.5}$ problems related to strong temperature inversions, low mixedlayer heights, and more recently extreme drought conditions. 
In the southern SJV weak surface winds and a unique basin topography add to the problem of stagnation and, in general, a strong temperature inversion exists aloft over the entire SJV, restricting the convective venting of pollution. Entrainment aloft becomes an even more important factor during stagnant conditions in the SJV because it represents the principal mode of ventilating the air pollutants in the ABL, and therefore its quantification is crucial to predicting the intensity and duration of an air quality episode.

Here we will present the results of two flight campaigns targeting the SJV in winter and summer, and show the utility of applying simple mixed-layer budget equations to airborne measurements in order to calculate entrainment velocities, and then apply these to get the entrainment rates of three trace gases: $\mathrm{O}_{3}, \mathrm{CH}_{4}$, and water vapor. With the additional measurements of these species' temporal trends and horizontal advection rates, important budget residuals are deduced such as $\mathrm{O}_{3}$ photochemical production, regional methane emissions, and latent heat fluxes. First we turn to a discussion of the uniqueness of the SJV, including the synoptic setting as well as the important mesoscale features. Then we describe the measurements used in the analysis along with the methods of ABL budgeting. In Sect. 3 we discuss the results from the analysis, provide a thorough assessment of the probable errors in the results in Sect. 4, and make some suggestions for further applications in our conclusions summarized in Sect. 5.

\section{Experimental description}

\subsection{Synoptic and geophysical setting}

The arid weather experienced throughout most of California during the summer is under the weight of the prevailing Pacific High, centered near $35^{\circ} \mathrm{N}$ some $2000 \mathrm{~km}$ offshore (Fig. 1, bottom right), which blocks storm systems from hitting the state instead shunting them northward towards Canada. The domineering anticyclone also drives synoptic scale subsidence on its downwind flank over the region. A strong thermodynamic "lid" or temperature inversion is set up by the synoptic subsidence, which resists convective motions throughout the lower atmosphere, leading to the collaboration of stagnant horizontal winds, sunny skies, and reduced vertical mixing that is emblematic of ozone pollution episodes. The zonal pressure gradient and surface friction impel a degree of onshore flow (atmospheric Ekman transport) that is principally blocked by the coastal mountains. The low-level summertime airflow into the interior of the state is therefore restricted to the main break in the Coast Range near the San Francisco Bay area and is strengthened by the land-ocean thermal contrast, with air entering the Carquinez Strait just beyond the San Francisco Bay and diverging into the conjoined Sacramento and San Joaquin valleys that together make up the great Central Valley of California
(Schultz et al., 1961; Frenzel, 1962; Hays et al., 1984; Moore el al., 1987; Zaremba and Carroll, 1999). This restricted airflow is the feedstock of the Central Valley air and is diverted north-northwest into the Sacramento Valley and southeast into the San Joaquin Valley as it abuts the tall Sierra Nevada. The SJV is flanked by three mountain ranges: the southern Sierra Nevada to the east, the Tehachapi Mountains to the south, and to the west the Pacific Coast Ranges, all limiting outflow and ventilation and leading to orographic stagnation and uplift towards the southern end of the valley. However, airflow at higher elevations over the valley air and surrounding mountains is entrained down into the valley boundary layer due to convective turbulent mixing during the daytime. It is precisely this mixing mechanism that is critical to understanding the setup and evolution of air pollution events in the valley, and what we set out to quantify in this study.

In the SJV a nonlinear superposition of flows dictates the observed winds. In addition to the synoptic forcing discussed above, there is a direct thermal forcing of the mountainvalley circulation with consequent up-slope flows inducing mesoscale subsidence over the central valley floor (Rampanelli et al., 2004; Schmidl and Rotunno, 2010). In the far southern end of the San Joaquin up-valley air is forced to converge as it runs into the steep topography of the Tehachapi Mountains. This low-level orographic convergence, which was shown in ABL wind data by Bianco et al. (2011), gives rise to mesoscale uplift especially pronounced at the cul-desac of the valley. Monthly composites of vertical velocity (omega) from the National Center of Environmental Prediction North American Regional Reanalysis (NCEP NARR) data set, averaged over the decade from 2004 to 2013, are depicted in Fig. 1. Upward motion is present across large swathes of the Central Valley during summer, likely due to orographic lift on the windward side of the Sierra Nevada range, but it appears especially strong in the southern end of the valley (Fig. 1) where the thermal valley wind and southern mountains augment the effect.

The complex mesoscale terrain plays a very important role in the valley atmosphere. The influence of topography on the thermally driven flow pattern arising from land-ocean contrast in the Californian Central Valley during the summer is discussed in Zhong et al. (2004). Their study employed the use of 22 wind profilers with radio acoustic sounding systems (RASS) to vertically probe the atmosphere. The authors suggest, based on temperature profiles in the lowest $800 \mathrm{~m}$, that the mixed-layer height, which probably exceeds $1000 \mathrm{~m}$ a.g.l., slopes up-valley in the San Joaquin. Additionally, the thermally driven flow pattern frequently extends upward to 800-1000 $\mathrm{m}$ a.g.l. Bianco et al. (2011), investigating various factors influencing ABL height in the Central Valley, reported low-level convergence in the southern end of the valley, leading to increased ABL heights. They did so by looking at the difference in up-valley wind between two sites in the SJV: Chowchilla and Lost Hills. This is in contrast to sites to the north in the SJV which see a shoaling in 

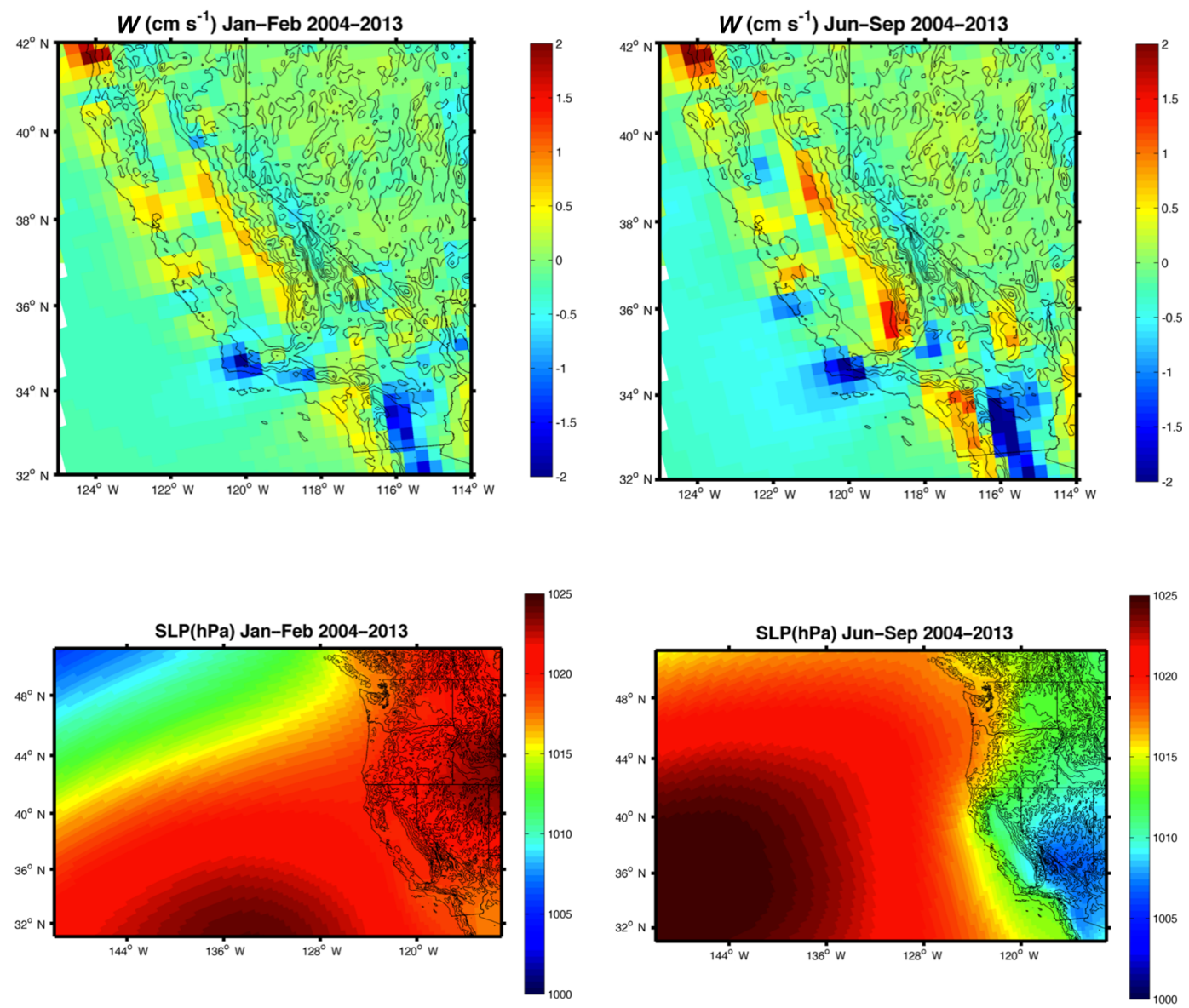

Figure 1. $W$ (vertical velocity), converted from omega (pressure velocity), at the $900 \mathrm{hPa}$ level and mean sea-level surface pressure. Plotted for two intervals, January-February and June-September, for 10 years from 2004 to 2013. The months chosen for the two separate plots represent the time frame of the flights. SLP: sea-level pressure.

the summer months, likely due to cold air advection from the coast, or subsidence induced from the valley flow (far from the valley's terminus at the Tehachapi Mountains), or possibly other causes such as land use, wherein different irrigation patterns may lead to a different partitioning of latent and sensible heat fluxes (Bianco et al., 2011). Our study corroborates the convergence in the southern end of the valley in that the NCEP NARR data set shows strong uplift at the southern extremity of the SJV, and that there is often an unmistakable decrease in wind speeds approaching the southern mountains observed by the aircraft winds (data not shown).

Seven flights from 16 January to 4 February 2013 were deployed across the San Joaquin Valley transverse to its axis with extensive vertical profiling of the ABL and the FT above it, in conjunction with the NASA DISCOVER-AQ California campaign (flight region 1, see Fig. 2). In each vertical profile up and down through the ABL we monitored the inversion height in addition to a suite of scalar measurements (ozone, water vapor, methane, horizontal winds, carbon dioxide, and temperature). In addition, on each profile we fly up through the ABL top in order to characterize the composition and thermodynamic properties of the FT. The second set of deployments was focused at the southern end of the SJV during the summer months, employing a slightly different flight strategy (flight region 2, see Fig. 2). Although vertical probing up and out of the ABL was similarly performed during this second experiment, a much greater emphasis was placed on the horizontal extent of the measurements in the direction of the mean ABL wind. The main focus of this campaign was to better understand the cause of the large number of ozone NAAQS exceedances in this region surrounding the small town of Arvin. To do so required a thorough quantification of the horizontal advection as well the entrainment flux of $\mathrm{O}_{3}$ (directly related to entrainment rates). Flights were targeted at $\mathrm{O}_{3}$ exceedance episodes with each of four deployments lasting 2-3 days spanning two summers (2013-2014) between June and September. 


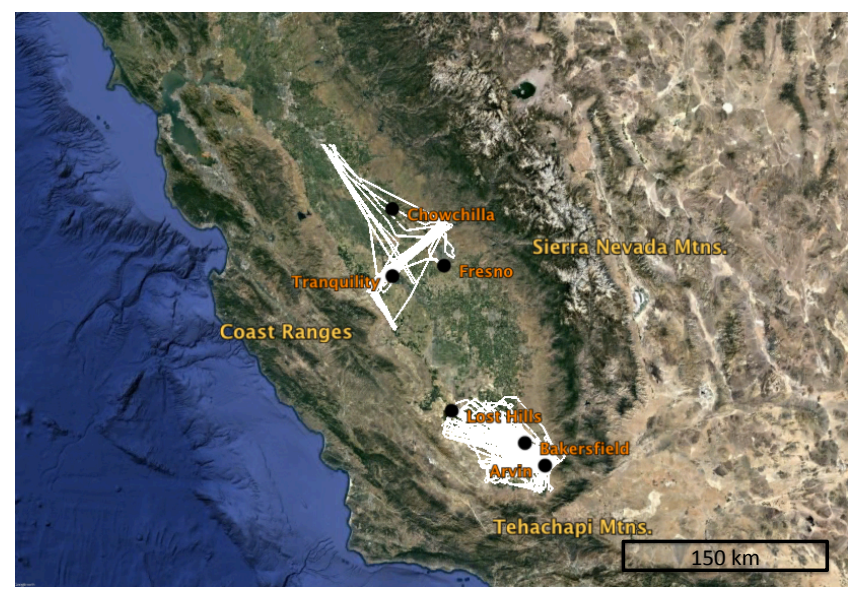

Figure 2. Flight paths of all data observed in the ABL for the two projects of this study: DISCOVER-AQ near Fresno from January and February 2013 (region 1), and the ArvinO3 project sampling from June to September over two summers and carefully mapping the inflow region upwind of Bakersfield and Arvin (region 2).

\subsection{Aircraft measurements}

Our flight data were collected aboard a single-engine Mooney TLS, operated by Scientific Aviation, Inc. (http: //www.scientificaviation.com), and piloted by one of the authors (Stephen A. Conley). The Mooney is outfitted with a 2B Technologies $\mathrm{O}_{3}$ monitor, a Vaisala HMP60 temperature and relative humidity probe, a modified Picarro $2301 \mathrm{f} \mathrm{Cav-}$ ity Ring-Down Spectrometer (CRDS) to measure $\mathrm{CO}_{2}, \mathrm{CH}_{4}$, and $\mathrm{H}_{2} \mathrm{O}$, and an Aspen Avionics PFD1000 flight display delivering pressure, altitude, true air speed, etc. Measurement of the horizontal wind is accomplished using a novel technique developed for easy and inexpensive deployment on a single-engine aircraft. Utilizing a dual GPS antenna to provide accurate airplane heading and a ground velocity by vector subtraction from true air speed (TAS), the horizontal wind is calculated - a technique outlined in Conley et al. (2014).

\subsection{Sortie strategies}

In order to support the objectives of the DISCOVER-AQ campaign by probing the boundary-layer dynamics near the northern edge of the domain, the aircraft was flown back and forth perpendicular to the valley axis approximately between the NASA profile stations at Fresno and Tranquility (Fig. 2). In the absence of making fast vertical wind measurements, we derive entrainment rates in a novel way using a complete scalar budget of the ABL height throughout each flight targeted from midday to late afternoon hours (usually 11:0016:00 PST). The flight hours are specifically chosen to focus on the ABL dynamics after its initial, rapid growth through the residual layer in the mid-morning. The inferred entrainment rates derived from the ABL height-budget, are then used in all of the scalar budgets to reveal $\mathrm{O}_{3}$ photochemi- cal production rates, surface latent heat fluxes, and regional methane emissions as residuals.

To study the processes that govern the evolution of the surface concentration of $\mathrm{O}_{3}$ during the summer months in the southern SJV in more depth, we performed an airborne experiment in collaboration with Scientific Aviation, Inc., targeting the vicinity of Arvin, California, during the summers of 2013 and 2014. Flying around and upwind of Arvin 3-7 h per day during each of the four 3 day campaigns, observations of wind, temperature, methane, water vapor, and ozone were used to measure the principal dynamical components of the total ozone budget: namely, advective up-valley transport within the $\mathrm{ABL}$ and entrainment mixing from above. By comparing these measured dynamical terms with the observed $\mathrm{O}_{3}$ rise throughout the region during the afternoon, and using a reasonable parameterization of dry deposition, the net photochemical production rate can be inferred. Consequently, the relative contributions of these processes to the resulting surface $\mathrm{O}_{3}$ concentration can be estimated for midday conditions, which are most important in determining whether an ozone exceedance of the NAAQS is reached. On one of the flights during the second deployment (15 August 2013) we additionally made $\mathrm{NO}_{2}$ measurements with a Los Gatos Research cavity enhanced absorption spectrometer. All flights, for both campaigns, targeted days with weak horizontal winds in the ABL because stagnation tends to accompany both wintertime $\mathrm{PM}_{2.5}$ and summertime $\mathrm{O}_{3}$ episodes.

\subsection{NARR data}

Because it is not currently possible to accurately measure mean vertical wind speeds by aircraft, we resort to the NCEP NARR data set to estimate the mean vertical wind speed at the top of the ABL during each flight. NARR is an extension of the NCEP global reanalysis, and was created to provide long-term consistent climate data focused over the US at a regional scale. The model runs at $32 \mathrm{~km}$ resolution with 45 vertical layers providing data eight times a day with a reanalysis period from 1979 to 2015. More information about this reanalysis data set can be found at http://www.esrl.noaa.gov/psd/data/gridded/data.narr.html.

\subsection{NOAA sounding system data}

We make heavy use of the data collected by NOAA during 2008 from five $915 \mathrm{MHz}$ radar wind profilers equipped with radio acoustic sounding systems distributed across the Central Valley and reported in Bianco et al. (2011). Briefly the radio signal backscatter is augmented in regions with strong fluctuations in temperature and water vapor as exists in the entrainment zone at the top of the ABL. The method of Bianco et al. (2008) uses not only the backscattered intensity, but further includes the vertical velocity variance and its spectral width to automatically select the ABL top throughout the day. The minimum gate height for these profilers 
is $120-140 \mathrm{~m}$ above ground, and their vertical resolution is $60 \mathrm{~m}$. To evaluate the average ABL growth rates we simply subtract the mean height at 11:00 from the mean height at 15:00 and divide by the $5 \mathrm{~h}$ interval.

\subsection{Budget of the ABL inversion height}

Quite often the growth rate of the boundary layer is interpreted as equivalent to the entrainment velocity, $w_{\mathrm{e}}$, or volume flux of FT air into the ABL (Tennekes, 1973), assuming that there is no large-scale mean vertical wind. However, in most situations the ABL growth $\left(\frac{\mathrm{d} z_{i}}{\mathrm{~d} t}\right)$ is actually determined by the difference of two distinct processes: the entrainment, which is considered to be driven by micrometeorological factors (viz. surface buoyancy flux, inversion strength, and possibly wind shear across the inversion), and the larger scale subsidence, $W$, in the lower FT just above the ABL, which is forced by synoptic flow patterns.

$w_{\mathrm{e}}=\frac{\mathrm{d} z_{i}}{\mathrm{~d} t}-W$

In a seminal paper on the effects of surface heating on the inversion height, Ball (1960) declared that there are several processes that counteract the tendency of entrainment to raise the inversion height. One is that "horizontal divergence in the lower layers, accompanied by subsidence at inversion level, may be sufficient to counteract the rise", and the other is that the "inversion usually slopes upward along the trajectories and thus advection tends to lower the inversion at a fixed point". To be even more precise then, we consider the total derivative of the ABL or mixed-layer height $\left(z_{i}\right)$ and expand it into the Eulerian derivative of ABL height and an advection term. The resultant $z_{i}$ budget equation leads to a relationship between the entrainment velocity, the observed local ABL growth rate, the mean advection of ABL depth, and the mean vertical velocity at the inversion height:

$w_{\mathrm{e}}=\frac{\partial z_{i}}{\partial t}+U \frac{\partial z_{i}}{\partial x}-W$

The first two terms on the right hand side of Eq. (2) are, in principle, easily observed by aircraft, while the last term has evaded careful measurement by aircraft or any other means (Lenschow et al., 1999, 2007; Angevine, 1997). While the sorties provided a sufficient number of ABL crossings to estimate the ABL growth rate with acceptable accuracy, there were generally not enough at different locations to capture an unbiased, two-dimensional gradient of the inversion height (second term on the right-hand side of Eq. 2). Consequently, we estimate the advection term using the gradient in ABL height as determined from the NCEP NARR data set in conjunction with the observed in situ mean wind (Fig. 3). The observations of $z_{i}$ indicate that the reanalysis data do not predict the absolute boundary-layer depth with great accuracy in the Central Valley. This is most likely due to the fact that the model does not treat the heavily irrigated agricultural land surface with any fidelity. Inspection of the surface latent heat fluxes in the model (data not shown) indicate unrealistically small values for a region with such fecund agricultural productivity. Nevertheless, we assume here that the reanalysis data do capture the gradients of ABL depth reasonably well. In fact, the gradients evinced in Fig. 3 are in rough accord with those reported in Bianco et al. (2011): for example, approximately $500 \mathrm{~m}$ difference across the lower $\sim 200 \mathrm{~km}$ of the southern SJV. The large-scale vertical mean wind, $W$, is derived from the NCEP NARR pressure velocity omega $\left(\omega=\frac{\mathrm{d} p}{\mathrm{~d} t}\right)$, and the surface pressure tendency neglecting horizontal pressure advection and assuming hydrostatic balance:

$W=\frac{1}{\rho g} \times\left(\frac{\partial p}{\partial t}-\omega\right)$.

The pressure level from which to select the omega value was chosen using the hypsometric equation $\left(p_{2}=p_{1} \times \exp \left(-\frac{z_{i} \times g}{R_{\mathrm{d}} \times \bar{T}_{\mathrm{v}}}\right)\right)$, using an average observed ABL height, $z_{i}$, an average ABL virtual temperature, $\bar{T}_{\mathrm{v}}$, for the flight duration, the dry air gas constant $R_{\mathrm{d}}$, and an estimated average surface pressure, $p_{1}$, of $1010.5 \mathrm{mb}$ for June-September, and $1020 \mathrm{mb}$ for January-February.

The local pressure change is estimated by the surface pressure tendency using hourly data from several CARB (The California Air Resources Board: http://www.arb.ca. gov/aqmis $2 /$ metselect.php) meteorology stations in the area over the flight time. Throughout the afternoon during both seasons the valley experiences a fairly strong and consistent drop in surface pressure of approximately $0.6 \mathrm{mb} \mathrm{h}^{-1}$. Similar diurnal oscillations of surface pressure were found by $\mathrm{Li}$ et al. (2009) to be prevalent in deep mountain valleys of the western US. Although these pressure changes are large by synoptic standards, they are generally an order of magnitude smaller than the omega values.

\subsection{Mixed-layer model framework}

Ultimately the estimation of the entrainment rate made by applying Eq. (2) to the aircraft measurements and reanalysis data is used to illumine the specifics of trace gas evolution by connecting it to their individual entrainment rates in each one's own budget equation. For example, the scalar budget of ozone in a well-mixed ABL can be mathematically represented as:

$\frac{\partial \mathrm{O}_{3}}{\partial t}=-U \frac{\partial \mathrm{O}_{3}}{\partial x}+\frac{\left(w^{\prime} \mathrm{O}_{3}{ }^{\prime}\right)_{\mathrm{s}}-\left(w^{\prime} \mathrm{O}_{3}{ }^{\prime}\right)_{z_{i}}}{z_{i}}+P$.

The first term on the left represents the observed temporal trend in a fixed region, the second term represents the advection (the influence of the mean wind, $U$, acting on the mesoscale gradient in the $\mathrm{O}_{3}$ field), $z_{i}$ is the ABL depth, the third term is the opposite of the vertical turbulent flux divergence, and $P$ represents the net photochemical production (Conley et al., 2011). We use observations and/or estimates of the first four terms of Eq. (4) to solve for the net 

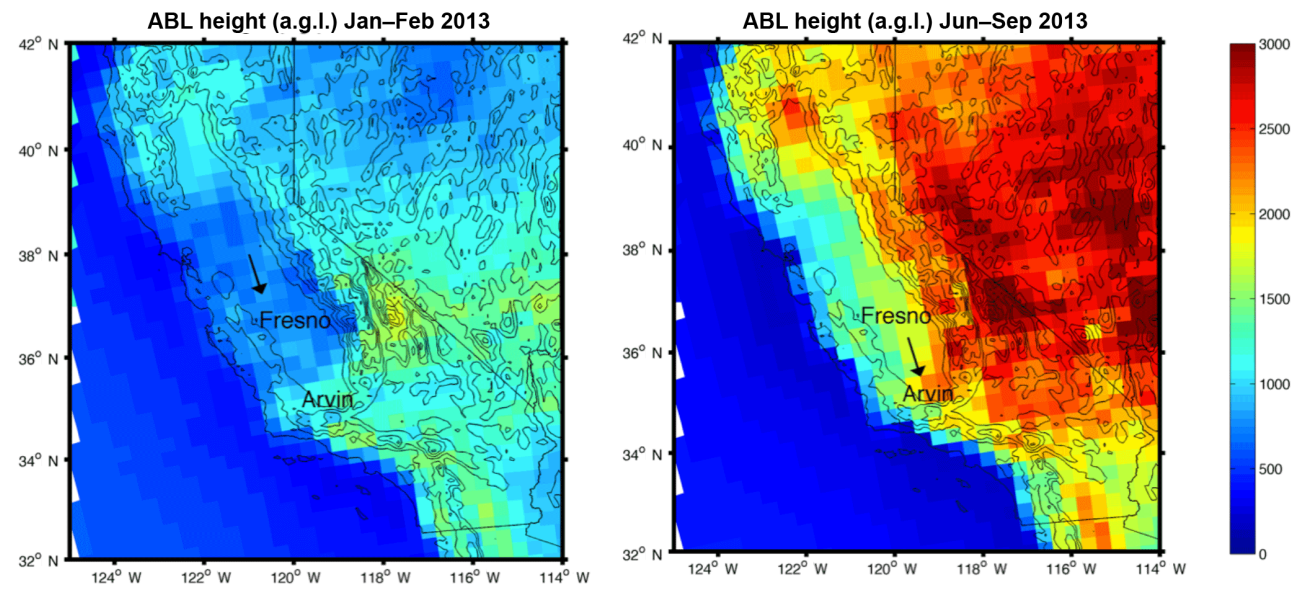

Figure 3. The average spatial pattern of boundary-layer heights from the NCEP NARR data set for (left) the winter period, and (right) the summer period of this study. Wind vectors represent the mean in situ winds measured by the aircraft near the ABL top.

production rate of ozone. The surface flux, $F_{\mathrm{s}}$, for a reactive species like ozone that is taken up in plant stomata is parameterized as the product of a deposition velocity, $v_{\text {dep }}$ and mean concentration, $F_{\mathrm{s}} \equiv\left(w^{\prime} \mathrm{O}_{3}{ }^{\prime}\right)_{\mathrm{s}} \cong-v_{\text {dep }}\left[\mathrm{O}_{3}\right]$. The entrainment flux, $F_{\text {ent }}$, on the other hand, is due to the mixing in of free tropospheric air at the top of the ABL, and is commonly parameterized as the product of the entrainment velocity of Eqs. (1) and (2), and the concentration difference (or scalar jump) across the inversion interface at $z_{i}$, $F_{\text {ent }} \equiv\left(w^{\prime} \mathrm{O}_{3}{ }^{\prime}\right)_{z_{i}} \cong-w_{\mathrm{e}} \Delta\left[\mathrm{O}_{3}\right]_{\mathrm{FT}-\mathrm{ABL}}$. This relationship applies to all the scalars and thus the determination of $w_{\mathrm{e}}$ feeds into each budget equation.

The scalar jumps are diagnosed from vertical profiles made during each flight (see Fig. 8 for an example). From experience, we have found it best not to attempt its determination with an algorithm, and instead calculate the jump from each vertical profile directly by eye, comparing concentrations from approximately the top half of the ABL with the lowest $\sim 100 \mathrm{~m}$ of the FT, assuming that the scale of turbulent entrainment is limited by the stability of the temperature inversion (Faloona et al., 2005) to $\sim 50-100 \mathrm{~m}$ above $z_{i}$. Errors in the jumps, estimated by the spread in the jumps and their approximate ambiguity, have been estimated to be $\sim 10-100 \%$ of the observed jumps (Tables S2 and S3 in the Supplement). The scalar jump $\left(\Delta[C]_{(\mathrm{FT}-\mathrm{ABL})}\right)-$ with $C$ representing a generic scalar such as ozone $\left(\mathrm{O}_{3}\right)$, water vapor $(q)$, or methane $\left(\mathrm{CH}_{4}\right)$ - is usually negative for a compound with a surface source (e.g., water, methane, and ozone precursors), and a positive entrainment velocity holds for a turbulent boundary layer, which tends to grow at that rate in the absence of mean vertical wind (Eq. 1). Therefore, the sign of the entrainment flux is positive, and upward due to the entrainment dilution of FT air into the ABL - a downward flux of concentration deficit is equivalent to an upward flux.

In the absence of clouds and precipitation (in situ sources or sinks) the water vapor budget equation is even simpler than that for ozone (Eq. 4):

$$
\frac{\partial q}{\partial t}=-U \frac{\partial q}{\partial x}+\frac{\left(w^{\prime} q^{\prime}\right)_{\mathrm{s}}+w_{\mathrm{e}} \Delta q_{\mathrm{FT}-\mathrm{ABL}}}{z_{i}}
$$

During our flights the first, second, and fourth terms above are measured by the aircraft allowing for the observation of the surface flux of water vapor. And in an exactly analogous manner we can use the aircraft measurements of methane to infer the surface flux, or average emission rate, of methane in the region. The surface latent heat flux, $\mathrm{LH}$, divided by the latent heat of vaporization, $L_{\mathrm{V}}, \frac{\mathrm{LH}}{L_{\mathrm{V}}}=\left(w^{\prime} q^{\prime}\right)$, was taken from the NCEP NARR data set, and found to significantly underestimate our estimates in the regions of interest. We then look to the reference evapotranspiration $\left(\mathrm{ET}_{o}\right)$ at various sites throughout the Central Valley from the California Irrigation Management System (CIMIS). $\mathrm{ET}_{o}$ comes from standardized grass or alfalfa over which the measurement stations are situated, and it includes loss of water from the soil and plant surfaces. Although agriculture is prevalent in the area of interest, it does not represent the entire land surface.

\section{Discussion of results}

Below we discuss the various important results that can be extracted from a flight strategy that is targeting a fixed region of $50-100 \mathrm{~km}$ scale and carefully tracking the changes in thermodynamic and chemical properties of the air mass. Because the sampling specifically targets the time of day when the boundary layer is actively entraining from the FT (excluding its initial phase of "encroaching" through the residual layer), all of the results for entrainment rates, surface emissions of methane, evapotranspiration, and in situ photochemical production pertain to the period from 11:00 to 16:00 local standard time. 


\subsection{ABL growth and entrainment rates}

The airborne data measuring ABL growth rates are used to diagnose the entrainment rate by budgeting of $z_{i}$ as expressed in Eq. (2). The average ABL heights (dashed lines) and their midday growth rates (slopes of dashed lines with shaded regions representing $\pm 1 \sigma$ of the observed growth rates) are shown for all the flights in Fig. 4 and compared with the corresponding RASS data presented in Bianco et al. (2011). The Chowchilla site is $50 \mathrm{~km}$ upwind from Fresno, and the Lost Hills site is just on the upwind edge of our sampling domain for the ArvinO3 study (Fig. 2). Both the boundarylayer depths and their growth rates measured in the airborne experiments appear to be slightly lower than the Bianco et al. (2011) seasonal averages. The discrepancy is probably attributable to both airborne experiments specifically targeting the stagnation, high-pressure synoptic settings that characterize both the wintertime $\mathrm{PM}_{2.5}$ and summertime ozone episodes, which in principle suppress ABL development due to subsidence. Table S1 in the Supplement summarizes the estimated entrainment velocities from the two experiments, but the average from the two missions can be viewed in Fig. 5, indicating a range from near zero (or below our detection limit of about $0.5 \mathrm{~cm} \mathrm{~s}^{-1}$ ) to $2.4 \mathrm{~cm} \mathrm{~s}^{-1}$ during the wintertime in the central SJV (average of $1.5 \pm 0.9 \mathrm{~cm} \mathrm{~s}^{-1}$ ), and approximately 0.9 to $6.5 \mathrm{~cm} \mathrm{~s}^{-1}$ during the summertime over the southern SJV (average of $3.0 \pm 2.1 \mathrm{~cm} \mathrm{~s}^{-1}$ ). Broadly comparable values have been observed in other continental studies: $4.3 \mathrm{~cm} \mathrm{~s}^{-1}$ during late July over grassland in the Netherlands in a study by Vilà-Guerau de Arellano et al. (2004), $1.4 \pm 0.3,5.5 \pm 1$, and $9.6 \pm 1.5 \mathrm{~cm} \mathrm{~s}^{-1}$ over the foothills of the Sierra Nevada adjacent to the California's Central Valley using isoprene flux measurements during June by Karl et al. (2013), and $5 \pm 1 \mathrm{~cm} \mathrm{~s}^{-1}$ over the Ozark mountains in the southeastern US during September by Wolfe et al. (2015). As far as we can tell, the data presented here are the first of their kind to estimate entrainment during the winter season, which, although observed to be smaller (as expected) because of weaker surface heating, are critical to understanding the meteorological influence on the valley's $\mathrm{PM}_{2.5}$ episodes.

The entrainment velocities estimated in the two studies show evidence that they are linked to physically relevant surface parameters present during the flights. For example, the summertime entrainment velocities correlate well with the average ABL potential temperature $\left(r^{2}=0.57\right.$, data not shown), insinuating that the forcing that heats the boundary layer (surface and consequent entrainment heat fluxes) is intimately linked to the entrainment rate. In a similar vein, the wintertime entrainment velocities correlate well with estimates of net surface radiation found in the NARR data set $\left(r^{2}=0.68\right.$, data not shown). A climatology of boundarylayer heights reported by Pal and Haeffelin (2015) near Paris showed that although surface heat fluxes should most directly control the boundary layer height, a better correlation was

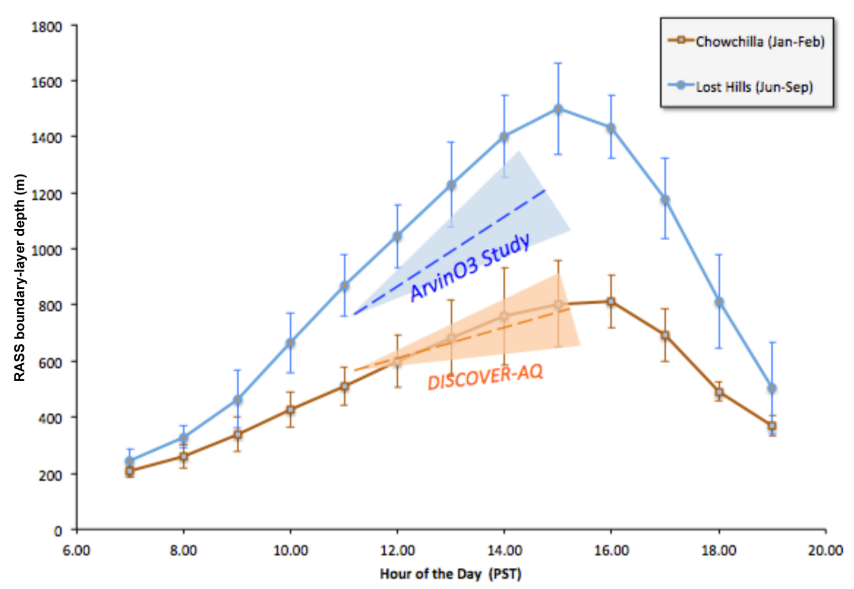

Figure 4. Diurnal boundary-layer development as observed during the two experiments presented here, and the average data from the corresponding months and locations presented in Bianco et al. (2011) as the solid line. The dotted lines are the average ABL growth rates from this study, for each respective mission, and the larger area represents the spread.
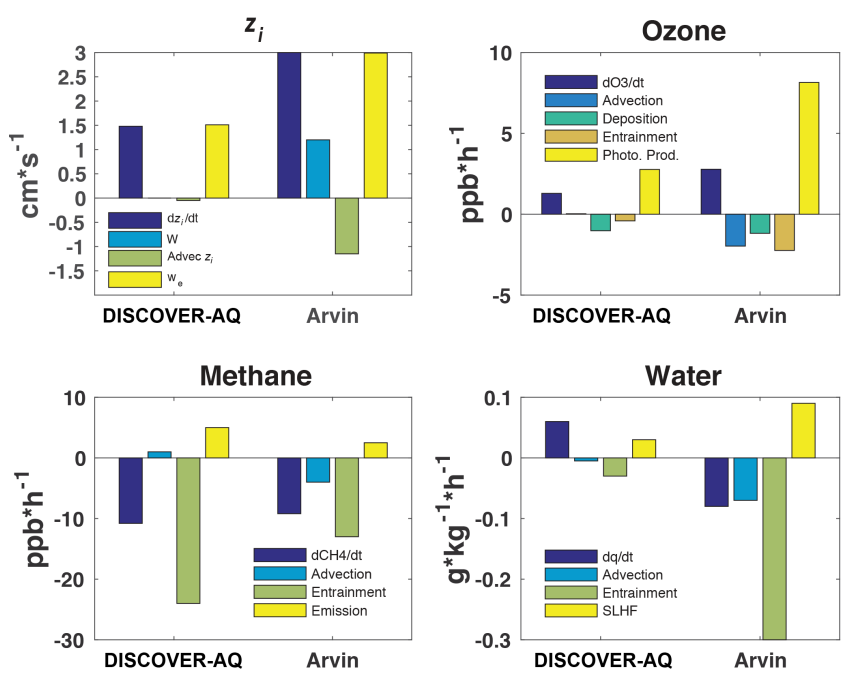

Figure 5. Individual budget terms for each scalar from the flight mission average corresponding to winter (DISCOVER-AQ) and summer (Arvin) in the SJV.

found, on diurnal to seasonal time scales, with the surface down-welling shortwave radiation. Although surface fluxes were not directly measured as part of the experimental setup, we turn to the surface solar radiation measured with pyranometers by the CIMIS network across the region. Figure 6 shows a very strong linear relationship with the surface pyranometer observations and the average boundary-layer height for each flight. In fact, the linear fits for each separate experiment seem to be the same within the uncertainties of the fits, and the slopes of $1.5 \mathrm{~m}\left(\mathrm{~W} \mathrm{~m}^{-2}\right)^{-1}$ are similar to those

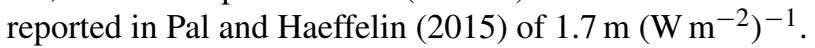




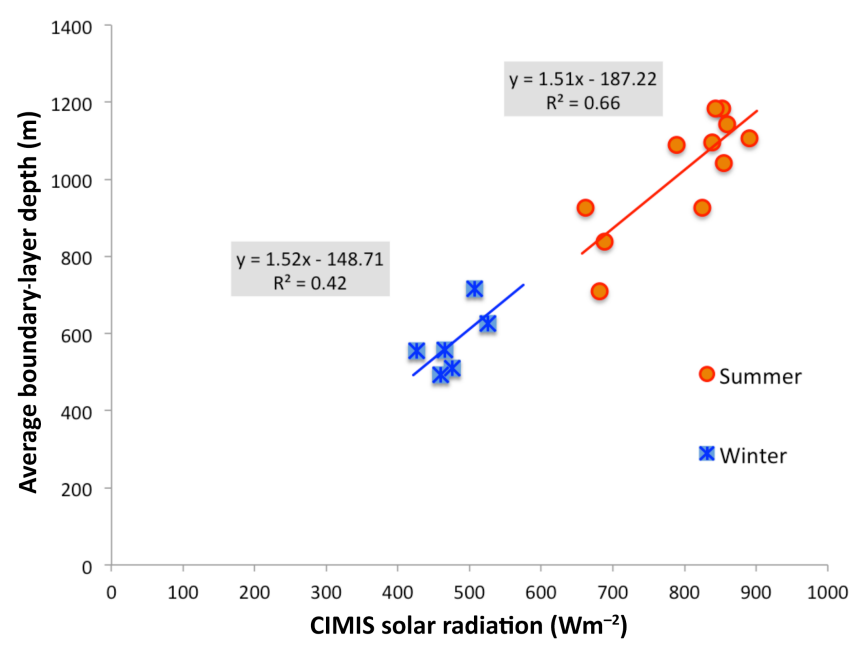

Figure 6. Flight averaged boundary-layer depths as a function of the surface downwelling solar radiation, as measured by the CIMIS station pyranometer in the flight regions near Fresno in winter, and Bakersfield in summer.

Pal and Haeffelin (2015) further survey nearly a dozen past studies that reported $\mathrm{ABL}$ growth rates over different seasons ranging from 0.8 to $8.3 \mathrm{~cm} \mathrm{~s}^{-1}$. There are two main reasons that these growth rates are not exactly comparable to the entrainment velocities reported here. First, most of these studies do not explicitly take into account horizontal or vertical $z_{i}$ advection (the last two terms in Eq. 2). Second, the convention used by many is to report $\mathrm{ABL}$ growth rates for the interval from when the surface heat flux reverses sign shortly after sunrise to the time when the boundary-layer height is $90 \%$ of its daily maximum. Such growth rates are thus a combination of the rapid growth through the nearly statically neutral residual layer in the morning and the slower growth near midday when the ABL is actively entraining air from the free troposphere. For the chemical budgets under consideration in this work, we contend that it is more important to quantify the late morning to early afternoon entrainment mixing between the ABL and FT, because entrainment of the residual layer in the early morning (sometimes called fumigation) represents merely a recycling of the previous day's boundary-layer air (albeit from sources an overnight advection scale of order $100 \mathrm{~km}$ away). For the purposes of estimating regional source strengths or regional in situ photochemistry, we suggest that the more pertinent mixing process is the dilution of the anthropogenically influenced ABL air mass by the more global "baseline" FT air, and we therefore exclude data from the morning period when the boundary layer is growing rapidly into the residual layer. Both of these differences lead to the realization that the ABL growth rates reported by Pal and Haeffelin (2015) and references therein, should be systematically larger than the entrainment velocities reported in this study, at least under fair weather conditions (subsidence). Our data from the DISCOVER-AQ win- tertime study presented in Fig. 5 (and Table S1 in the Supplement) indicate that the advection and subsidence terms may not be first-order, especially for longer period averages, and therefore may be comparable to other ABL growth rate statistics reported in the literature. This conjecture is consistent with conclusions from previous budget studies indicating that while advection may make a significant contribution to the scalar budget on any specific day, it may average out when considered on longer intervals (Conley et al., 2009; Faloona et al., 2010). A similar argument can be made for the vertical velocity term in Eq. (2); namely, that it may average to near zero across periods of instability and uplift, and periods of fair weather and subsidence. In a similar vein, the average $z_{i}$ budgets for the southern SJV (ArvinO3 in Fig. 5 and Table S1) show a sizeable average orographic uplift and opposing horizontal advection of $z_{i}$, which together may be in a quasi-steady state nearly canceling over long periods of weeks to months.

It follows that although not exactly equivalent to entrainment as described by Eq. (2), the range of ABL growth rates reported in the literature (from Pal and Haeffelin, 2015, and references therein) is nonetheless reasonably consistent with the data reported in Table S1. In the studies that report both winter and summer seasonal average ABL growth rates (Chen et al., 2001; van der Kamp and McKendry, 2010; Lewis et al., 2013; Schween et al., 2014; Korhonen et al., 2014; and Pal and Haeffelin, 2015), the summer to winter ratios tend to range from 1.4 to 3.0, with an average of 2.0. This is consistent with our results that indicate entrainment rates $80 \%$ higher in the SJV during summer than winter.

Bianco et al. (2011) postulate that convergence at the southern end of the SJV in summer leads to deeper ABLs there than in other parts of the valley, closer to the delta inflow region, which are influenced by strong marine-layer inflow. A typical slope of ABL height up the SJV from Bianco et al. (2011) can be estimated from the Chowchilla and Lost Hills sites, which differ by about $750 \mathrm{~m}$ (from their Fig. 2) over a distance of approximately $175 \mathrm{~km}$ for the summer months. Applying to this gradient a calculated average alongvalley wind at the top of the ABL of $2.5 \mathrm{~m} \mathrm{~s}^{-1}$ gives an advection term of $-1.1 \mathrm{~cm} \mathrm{~s}^{-1}$. This estimate compares well to the $-1.15 \mathrm{~cm} \mathrm{~s}^{-1}$ shown visually in Fig. 5, derived from the NARR data set from our flight region 2 during summer. In addition, Bianco et al. (2011) make a rough estimate of convergence in the southern SJV by simply taking the difference in the horizontal along-valley wind at the two sites $\left(2.5 \mathrm{~m} \mathrm{~s}^{-1}\right.$ between June and September), divided by the distance between them, leading to ABL flow convergence of $1.4 \times 10^{-5} \mathrm{~s}^{-1}$. Such convergence would lead to an uplift of $1.4 \mathrm{~cm} \mathrm{~s}^{-1}$ at the top of a typical $1000 \mathrm{~m}$ boundary layer. This estimate is, again, right inline with our estimates from this study. From our findings it appears that the local-time rate of change of observed ABL height nearly matches the entrainment rate when both are averaged over all the flights. The convergent uplift and the advection of ABL height appear to 

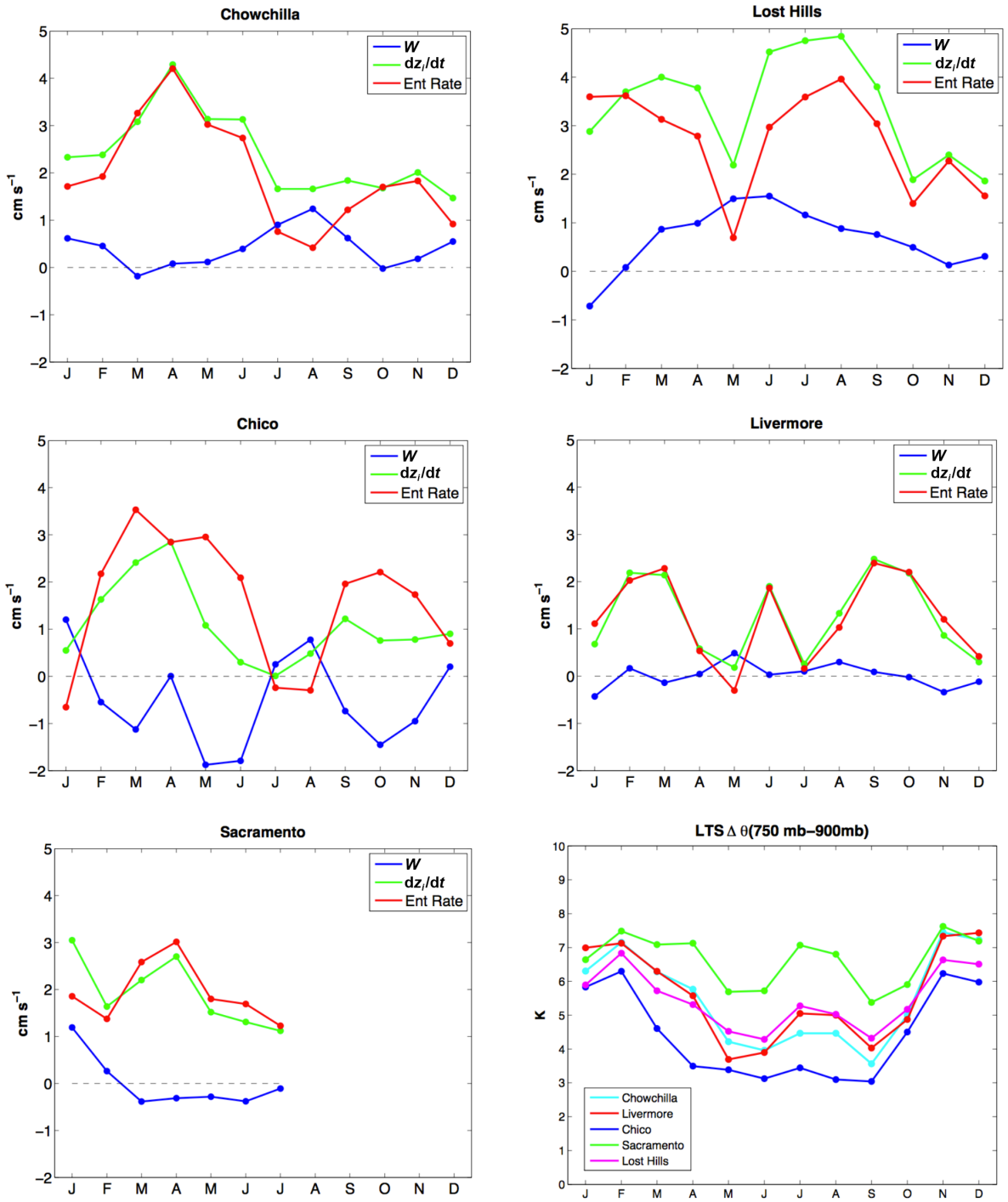

Figure 7. Observed monthly average ABL growth rates $\left(\mathrm{d} z_{i} / \mathrm{d} t\right.$, green lines) from the RASS network across the Central Valley described in Bianco et al. (2011) from the entire year of 2008. The mean vertical wind from the NCEP NARR data set is included (blue lines) to yield estimates of entrainment (red lines). The lower right panel depicts the lower tropospheric stability (LTS) defined from the reanalysis data as the difference in potential temperatures at 750 and $900 \mathrm{hPa}$ levels.

balance on average in the southern SJV. This suggests that the radio acoustic wind profiler data in the SJV, reported by Bianco et al. (2011), could be used to estimate entrainment rates by simply measuring the boundary-layer growth during the midday.

This idea is explored in Fig. 7, where we show the monthly average ABL growth rates observed year-round by NOAA's wind profiler network operated across California's Central Valley during 2008 (Bianco et al., 2011). Additionally, the monthly average subsidence at boundary-layer height is shown as captured in the NARR data set. Assuming that the advection term does not dominate at any of the sites in a long-term average (other than at Lost Hills where it is possibly counterbalanced by the convergent uplift), we can get a sense of the general entrainment characteristics across the Central Valley throughout the year. For example, there appears to be stronger entrainment at lower latitudes in the valley $\left(\sim 3 \mathrm{~cm} \mathrm{~s}^{-1}\right.$ annual peaks in the Sacramento Valley vs. $\sim 4 \mathrm{~cm} \mathrm{~s}^{-1}$ peaks in the San Joaquin Valley), possibly due to greater shortwave forcing or generally weaker stratification in the lower FT. It further seems that at most sites there is a definite peak in entrainment during the spring but also a secondary maximum in the autumn with a minimum during the mid-summer. This corresponds to the lowest ABL depths observed in the middle of summer as discussed by Bianco et al. (2011). In their analysis the authors suggest that the lower inversion heights of mid-summer are due to greater cold air advection through the delta and/or possibly the peak in irriga- 
tion in the heavily agriculturally controlled landscape of the Central Valley. Both effects serve to cool the ABL, thereby increasing lower tropospheric stability (LTS) and suppressing entrainment. The lower right panel in Fig. 7 shows the LTS, as measured by the difference in potential temperatures between 750 and $900 \mathrm{hPa}$ from NARR. The LTS minima in spring and autumn appear to not coincide exactly with the peaks in entrainment, but rather follow (spring) or presage (autumn) them by a month or two.

\subsection{Other budget residuals}

Once the entrainment rate has been calculated for each flight it can be used to close the other scalar budget equations and calculate any single residual term, assuming all the others have been characterized. The time derivative and gradient terms were all calculated by applying a simple multi-linear regression on all flight data collected below the (time varying) ABL height as described in Conley et al. (2009). The averaged budget terms for each respective mission can be viewed in Fig. 5, which serves as a visual aid to refer back to in the following sections. For more detailed breakdown see the Supplement, which includes the data for each individual flight.

\subsubsection{Ozone photochemical production}

Figure 8 illustrates the distinction between ABL and FT air and the importance of entrainment mixing on an ozone exceedance day. The potential temperature and specific humidity on the left graph show the surface heating and nearly wellmixed ABL capped by the stable inversion with dry, warm air aloft. The right hand graph shows the enhanced $\mathrm{NO}_{2}$ and $\mathrm{O}_{3}$ within the $\mathrm{ABL}$ during the day because of the surface emissions of $\mathrm{NO}_{x}$ and the photochemical production of $\mathrm{O}_{3}$ from those emissions in conjunction with reactive volatile organic compounds (RVOC). The ABL top, $z_{i}$, is indicated by the dashed line near $850 \mathrm{~m}$. Given the jumps in $\mathrm{O}_{3}$ and $\mathrm{NO}_{2}$ evident at that height, and the estimated mean entrainment velocity for the entire flight, $5.1 \mathrm{~cm} \mathrm{~s}^{-1}$ (Table S1, Supplement), the effect of entrainment dilution alone is causing a drop in surface $\mathrm{O}_{3}$ and $\mathrm{NO}_{2}$ concentrations by 4.0 and $0.32 \mathrm{ppb} \mathrm{h}^{-1}$, respectively, demonstrating how important entrainment can be for understanding the temporal evolution of air pollutants measured near the surface. The consequences of horizontal advection can be seen in Fig. 9, which shows the spatial distribution of $\mathrm{O}_{3}$ and $\mathrm{NO}_{2}$ measured by the aircraft during the same day, 14 August 2013. The grey lines indicate the flight path over the course of the day, and because $\mathrm{O}_{3}$ rises steadily throughout the flight, all the data are corrected to a common time (13:30 PST) by the observed mean temporal trend of $2.4 \mathrm{ppb} \mathrm{h}^{-1}$ and interpolated to a $\sim 2 \mathrm{~km}$ grid across the domain. The spatial pattern shows a strong negative $\mathrm{O}_{3}$ advection of $-2.5 \mathrm{ppbh}^{-1}$ into the Arvin area, but a countervailing positive $\mathrm{NO}_{2}$ advection. Thus while con-
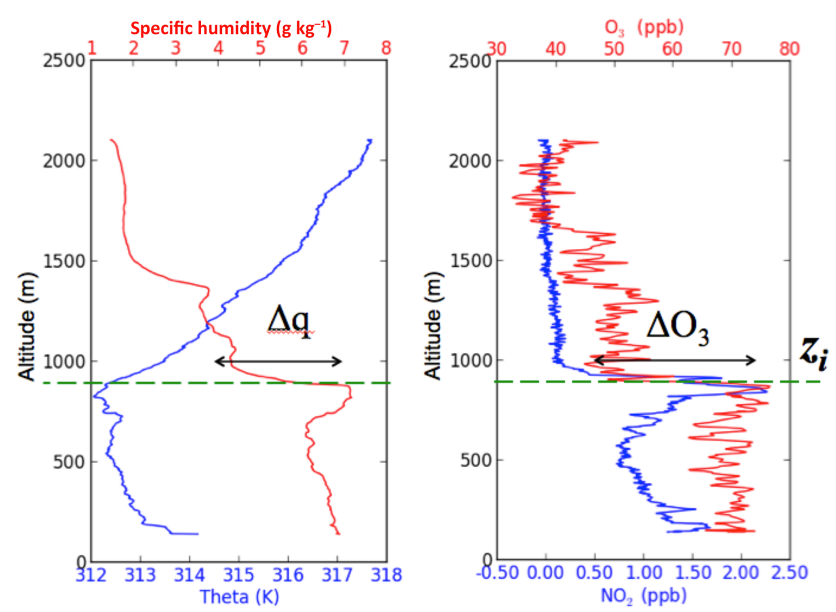

Figure 8. Example of vertical profiles of potential temperature (theta) and specific humidity $(q)$ on the left, and ozone and $\mathrm{NO}_{2}$ observed on the right during the flight on 14 August 2013 near Bakersfield, $\mathrm{CA} ; z_{i}$ is the estimated height of the ABL determined by the scalar jump ( $\Delta q$ and $\Delta \mathrm{O}_{3}$ shown here) across the entrainment zone.

sideration of the $\mathrm{O}_{3}$ budget requires taking into account this inflow of lower $\mathrm{O}_{3}$, the selfsame flow carries with it abundant precursors that boost the in situ $\mathrm{O}_{3}$ production near Arvin, the term that we infer through closure of the overall budget. This distribution of higher $\mathrm{O}_{3}$ around Arvin was not observed on every day, but was more common on ozone exceedance days. Because we only measured the $\mathrm{NO}_{2}$ distribution once, it is more difficult to generalize, but the local maximum of $\mathrm{NO}_{2}$ near Bakersfield has been reported elsewhere and is evident in seasonal satellite averages reported in Russell et al. (2010) and Pusede and Cohen (2012). The colored circles in Fig. 9 are the 13:00-14:00 hourly average values from the CARB surface air quality network, and by and large confirm the large-scale gradients observed by the aircraft.

In addition to applying our derived entrainment rates to close the $\mathrm{O}_{3}$ budget (Eq. 4), results from which are presented in Table S2 in the Supplement, we estimated the dry deposition term using a deposition velocity of $0.5 \mathrm{~cm} \mathrm{~s}^{-1}$, with an estimated uncertainty of $\pm 0.25 \mathrm{~cm} \mathrm{~s}^{-1}$, based on values reported in the literature for similar environments (Padro, 1996; Macpherson et al., 1995; Pio et al., 2000). The deposition term is the product of the deposition velocity and average ABL concentration divided by the ABL height. Dry deposition velocities are often reported with respect to a $10 \mathrm{~m}$ measurement, and although the lowest safe flight altitude is $150 \mathrm{~m}$ and we therefore do not have $\mathrm{O}_{3}$ measurements at $10 \mathrm{~m}$ (aside from takeoffs and landings), the vertical gradients of $\mathrm{O}_{3}$ tend to be no more than about $1 \mathrm{ppb}$ per $100 \mathrm{~m}$ (Fig. 8), so we consider the uncertainty in the $10 \mathrm{~m}$ concentration to be $\sim 2 \mathrm{ppb}\left(3-4 \%\right.$ the mean $\left.\mathrm{O}_{3}\right)$, and insignificant compared to the uncertainty in the deposition velocity of $50 \%$. Ozone photochemical production $(P)$ was 


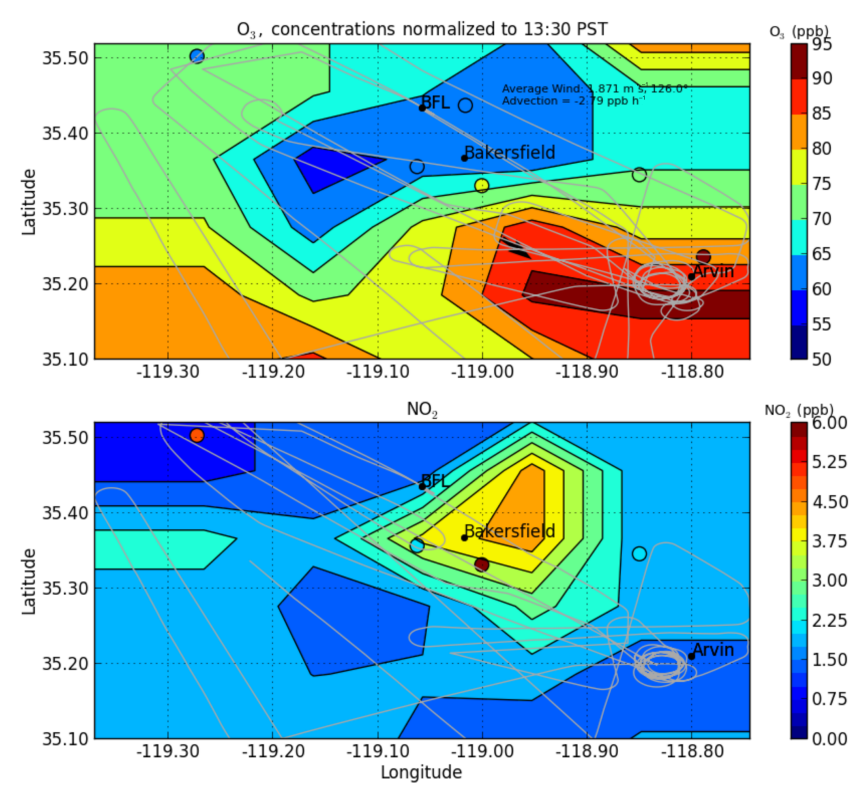

Figure 9. Horizontal patterns of $\mathrm{O}_{3}$ (top) and $\mathrm{NO}_{2}$ (bottom) during an ozone exceedance episode near Bakersfield on 14 August 2013. The grey lines represent the flight tracks, and the colored circles represent the surface network observations. Because of the continual trend in ozone throughout the flight, the values in the top figure are all corrected to a reference time of 13:30 PST. The black arrow in the top figure represents the vector average wind observed in the ABL during that sortie showing a strong negative advection of ozone and a large positive advection of $\mathrm{NO}_{2}$ into the Arvin region to the south. BFL is the Meadows Field Airport on the north end of urban Bakersfield. The colored circles represent the 13:00-14:00 surface site measurements from the ARB surface network.

estimated to be between 4.1 and $14.2 \mathrm{ppbh}^{-1}$ in summer and 2.1-3.9 $\mathrm{ppb} \mathrm{h}^{-1}$ in the winter. Comparisons between the winter and summer data sets are relevant. Although differences between the two sites could, in principle, arise due to varying local sources between Fresno and Bakersfield, the photochemical production is expected to be much lower in the winter with reduced actinic radiation fluxes. Note that there is almost a tripling of the photochemical production between the two seasons, in winter the average is $2.8 \mathrm{ppbh}^{-1}$ and in summer $8.2 \mathrm{ppbh}^{-1} \cdot \mathrm{O}_{3}$ production in the southern SJV, during the warm season, is believed to be $\mathrm{NO}_{x}$ limited for most conditions except for weekdays (higher $\mathrm{NO}_{x}$ on average) when temperatures exceed $29^{\circ} \mathrm{C}$, as proposed by Pusede et al. (2014), who investigated various factors in the production of ozone in the SJV. All of those conditions were met for the flights in the ArvinO3 study, and with the continued decrease in $\mathrm{NO}_{x}$ expected from the seven year trend of $-32 \%$ in Bakersfield reported by Russell et al. (2010) based on OMI satellite measurements of column $\mathrm{NO}_{2}$, the conditions are only becoming more and more frequently $\mathrm{NO}_{x}$-limited. A VOC : $\mathrm{NO}_{x}$ ratio proxy was derived from the airborne measurements of methane mi- nus the global background methane from NOAA's Global Greenhouse Gas Reference Network (http://www.esrl.noaa. gov/gmd/ccgg/trends_ch4/) divided by the CARB surface air quality monitoring network $\mathrm{NO}_{x}$ concentrations measured during the flight hours. Although the VOC makeup of the SJV is fairly complex due to the preponderance of dairy farms and natural gas production, both of these source types are strong methane emitters (Gentner et al., 2014), so we consider observed methane to be a decent, albeit flawed, proxy for the overall abundance of non-methane VOCs. Figure 10 shows that the inferred $\mathrm{O}_{3}$ production rates from both studies (Table S2) decrease with increasing VOC: $\mathrm{NO}_{x}$ ratio proxy indicating that the SJV is mostly under $\mathrm{NO}_{x}$-limited conditions.

Using a simplified box model constrained by observations of $\mathrm{NO}_{x}$ and $\mathrm{OH}$ reactivity, Pusede et al. (2014) estimate $\mathrm{O}_{3}$ production rates ranging from 10 to $26 \mathrm{ppbh}^{-1}$ at the Bakersfield CalNex supersite during May-June 2010. This is approximately double the rates reported in this study using the budgeting technique, $4-14 \mathrm{ppb} \mathrm{h}^{-1}$ (Table S2), with an average uncertainty estimated to be $\sim 1.3 \mathrm{ppbh}^{-1}$. The results reported by Pusede et al. (2014) are not net, but only the sum of the $\mathrm{O}_{3}$ photochemical production channels. However, Pusede et al. (2014) estimate that the $\mathrm{O}_{3}$ photochemical loss rates rarely exceed $\sim 1.5 \mathrm{ppbh}^{-1}$, and we thus assume that this can only be a small part of the difference between our estimates and theirs. A much more significant difference is likely because of the fact that Pusede et al. (2014) use measurements made inside the metropolitan area of Bakersfield, while the flight data represent a region of about $4600 \mathrm{~km}^{2}$ in which most of the land use is agricultural. Therefore, we expect the regional $\mathrm{O}_{3}$ production to be smaller because it incorporates land outside of the urban center where the $\mathrm{NO}_{x}$ is likely to be considerably lower on average (Pusede and Cohen, 2012). Another estimate (Brune et al., 2016) from the same experiment reports midday ozone production rates of $\sim 5 \mathrm{ppbh}^{-1}$ from $\mathrm{HO}_{2}$ alone, and assuming the organic peroxy radicals are nearly equivalent (as is often done, see Pusede et al., 2014 for example), then the total ozone production amounts to $\sim 10 \mathrm{ppbh}^{-1}$ in decent agreement with our measurements reported here. In a much earlier airborne attempt made at several sites across Europe and Asia, Lehning et al. (1998) estimate $\mathrm{O}_{3}$ production in a similar way to ours but neglect temporal trends and dry deposition to come up with 2.5-3.5 $\mathrm{ppbh}^{-1}$. Our estimates of those terms for the summer study sum to about 4 additional $\mathrm{ppb} \mathrm{h}^{-1}$, which would mean that their net photochemical production term could amount to $6.5-7.5 \mathrm{ppbh}^{-1}$, not far from our average of $8.1 \mathrm{ppbh}^{-1}$.

Baidar (2013) performed a budget study based on a research flight conducted on 15 June 2010 in and around Bakersfield. Amongst the objectives of the study was the determination of an emission rate for $\mathrm{NO}_{x}$ and $\mathrm{O}_{x}\left(\mathrm{O}_{3}+\mathrm{NO}_{2}\right)$ production rates from the urban area. They attempted a similar scalar budget approach using flight data obtained by remote 


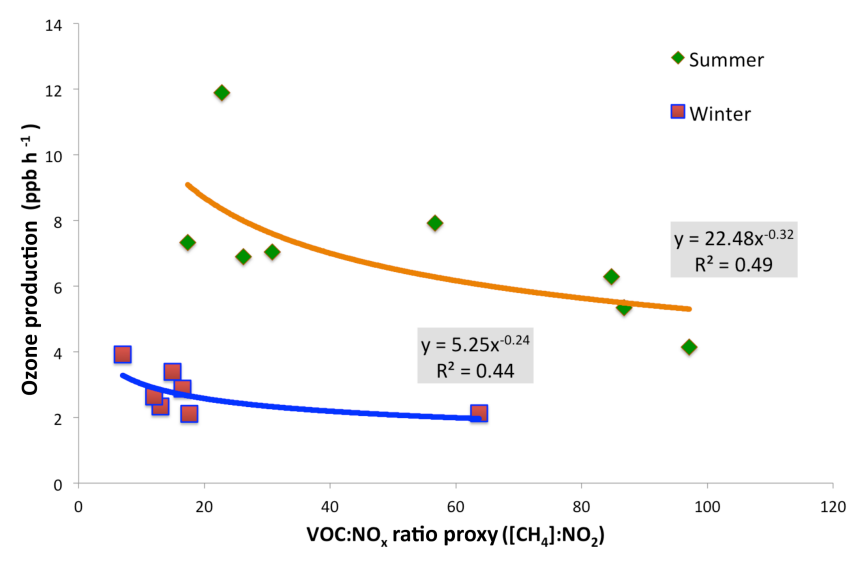

Figure 10. Plot of measured ozone production from the DISCOVER-AQ campaign near Fresno during winter (maroon squares) and from the ArvinO3 study during the summer (green diamonds) vs. a proxy of the $\mathrm{VOC}: \mathrm{NO}_{x}$ ratio estimated by the measured $\mathrm{CH}_{4}$ enhancement over global background divided by the $\mathrm{NO}_{x}$ measured during the flights from the CARB air quality monitoring network nearby.

sensing instruments (three different lidar systems) aboard the NOAA Twin Otter, obtaining a range of $\mathrm{O}_{3}$ production rates from 2.9 to $6.6 \mathrm{ppbh}^{-1}$ with an area weighted average of $4.0 \mathrm{ppb} \mathrm{h}^{-1}$. Within their volume of interest, they assumed the time rate of change of $\mathrm{NO}_{x}$ and $\mathrm{O}_{x}$ were zero and that the horizontal flux divergence alone determines the source strength for their region. Aside from temporal changes (storage terms), they further neglected entrainment and dry deposition fluxes of these constituents. From their Fig. 5 indicating the diurnal signal of $\mathrm{NO}_{x}$ and $\mathrm{O}_{x}$ taken from the Bakersfield CARB monitoring station, we estimate a $2.2 \mathrm{ppbh}^{-1}$ change in $\mathrm{O}_{3}$ during their measurement time. In addition, they estimate a potential error of not including vertical mixing, or entrainment, to be less than $2 \%$. Their estimate of the entrainment rate is on the low end of our range, at $1.2 \mathrm{~cm} \mathrm{~s}^{-1}$, but when calculating their entrainment flux they use a delta $\mathrm{O}_{x}$ of about $-4 \mathrm{ppb}$. Using our average observed jump across the ABL top of $-13.4 \mathrm{ppb}$, an average entrainment velocity of $3.0 \mathrm{~cm} \mathrm{~s}^{-1}$, and an average boundary-layer height of $1000 \mathrm{~m}$, along with a dry deposition velocity of $0.5 \mathrm{~cm} \mathrm{~s}^{-1}$, the vertical terms give rise to a loss rate of approximately $2.6 \mathrm{ppbh}^{-1}$. This could explain the difference between their average of $4.0 \mathrm{ppbh}^{-1}$ and our average of $8 \mathrm{ppbh}^{-1}$. But the comparison is imperfect because the ArvinO3 study specifically targeted ozone exceedance events (albeit only capturing 4 NAAQS and 6 California state exceedance days out of 11 flight days). During the day of the Baidar (2013) study the $\mathrm{O}_{3}$ peaked at only $\sim 65 \mathrm{ppb}$ based on the CARB surface monitoring network. Nevertheless, the comparison further points to the importance of treating all the budget terms in estimating net photochemical $\mathrm{O}_{3}$ production. In our study the contribution to the $\mathrm{O}_{3}$ budget from entrainment dilution is typically the same magnitude as the observed rise in $\mathrm{O}_{3}$, and the latter alone only constitutes one-third of the net photochemical production.

\subsubsection{Methane emission}

For a scalar such as methane undergoing extremely slow chemistry (with a photochemical lifetime of about a decade), the budget equation can be easily solved for the surface emission rate:

$$
F_{\mathrm{s}}=\left(U \frac{\partial \mathrm{CH}_{4}}{\partial x}+\frac{\partial \mathrm{CH}_{4}}{\partial t}\right) z_{i}+F_{\mathrm{ent}},
$$

where the advection and temporal trend terms are observed directly by the aircraft, and $F_{\text {ent }}$, the entrainment flux, is estimated using the parameterization of Eq. (5) based on the observed jump in $\mathrm{CH}_{4}$ across the ABL top and the entrainment velocity derived from the ABL height budget. Regional methane emissions from the DISCOVER-AQ campaign near Fresno were estimated to be $100 \pm 100 \mathrm{Gg} \mathrm{yr}^{-1}$, and from the Arvin-Bakersfield region they were estimated to be $170 \pm 125 \mathrm{Gg} \mathrm{yr}^{-1}$ when averaged over each respective flight campaign. The second numbers reported above represent the estimated standard deviation of the mean value representing the spread in the measurements across the different days of each campaign, not the estimated error in the measurements themselves. To obtain our in situ emission estimate we multiplied our regionally averaged surface methane emission by the approximate horizontal area encompassed by the series of flights. For flight region one we estimated the horizontal area to be $9.5 \times 10^{8} \mathrm{~m}^{2}$ because the flight pattern was simply across valley and the horizontal winds were light so there was little need to probe the direction of the mean advection. Flight region two covered a much larger area of $3.5 \times 10^{9} \mathrm{~m}^{2}$ because the experiment specifically targeted a careful mapping of the up-valley advection term in the $\mathrm{O}_{3}$ budget. In a recent work by Kort et al. (2014), using the Scanning Imaging Absorption Spectrometer for Atmospheric Chartography (SCIAMACHY) instrument from 2003-2009, the column-averaged $\mathrm{CH}_{4}$ mole fractions over the US are used to estimate surface emissions. Although the thrust of that study was the "hotspot" observed over the four corners region of New Mexico, it is interesting to note that the second largest spot (their Fig. 1) that emerges in the satellite climatology is located in the southern San Joaquin Valley of California. Using the California Greenhouse Gas Emission Measurement (CALGEM; http://calgem.lbl.gov/prior_emission.html) inventory we estimated the emissions from each sector for both flight regions. The emission estimates have been scaled to the 2013 total $\mathrm{CH}_{4}$ emission estimate for California of $41.1 \mathrm{Tg} \mathrm{CO}_{2} \mathrm{eq}$ provided by CARB. Inventory emissions from flight region one was found to be a total of $27.7 \mathrm{Gg} \mathrm{yr}^{-1}$ and from region two $71.1 \mathrm{Gg} \mathrm{yr}^{-1}$. Comparing these to the in situ estimates of this study, we find our estimates to be 3.6 and 2.4 times 
greater than the scaled CALGEM inventory estimates, respectively. According to the breakdown in sources found in the CALGEM database we estimated the fractional coverage of each source type for the two experiments. The first region sampled in winter near Fresno for the DISCOVER-AQ project was found to bear $54 \%$ fossil-fuel-related sources, with the majority of the balance coming from dairies $(25 \%)$ and other livestock $(9 \%)$ and landfills $(11 \%)$. Flight region two, flown during the summertime around Bakersfield, was more dominated by dairies $(73 \%)$, with most of the rest fossil-fuel-related (17\%). The difference in make-up of the two regions is broadly consistent with the finding expounded by Miller et al. (2013) that ruminant sources of methane appear to be approximately twice as large as current inventories hold, while fossil fuel sources are nearly six times larger than the present inventories indicate. This could account for the greater discrepancy found in the DISCOVER-AQ data where observed emissions are more heavily influenced by sources associated with fossil fuels.

To further examine the observed variability of the methane emissions in the southern SJV, where the sources are predominantly from dairies and thus derive from enteric and manure methanogenesis, the temperature dependence is presented in Fig. 11 in an Arrhenius plot. In general, the temperature response of microbial activity (ultimately the source of methane emission associated with livestock) is often quantified by an Arrhenius equation: i.e., rate $=$ $A \times \exp \left(-E_{\mathrm{a}} / R T\right)$, where $A$ is a pre-exponential factor, $E_{\mathrm{a}}$ is the activation energy, $R$ is the universal gas constant $\left(8.314 \mathrm{~J} \mathrm{~mol}^{-1} \mathrm{~K}^{-1}\right)$, and $T$ is the absolute temperature. Figure 11 shows the natural $\log$ of our estimates of methane emissions, at temperatures below the optimum (peak methane production occurs in the mesophilic range of $30-37^{\circ} \mathrm{C}$ ). The results of Elsgaard et al. (2016) indicate a peak in methane production near $38^{\circ} \mathrm{C}$ in cattle slurries. In order to compare most appropriately, we removed the $\mathrm{CH}_{4}$ emission rate estimate of the flight of 9 June 2014 when the air temperatures exceeded $39^{\circ} \mathrm{C}$, and we set the emission estimate to 0 (from $-20 \mathrm{Gg} \mathrm{yr}^{-1}$, within the method's uncertainty) for the 30 September flight, which was the coldest day of the experiment (afternoon average surface temperature in Bakersfield of $25.7^{\circ} \mathrm{C}$ ). The resultant data in Fig. 11 show signs of an Arrhenius-type behavior in the dominant methane sources in the southern end of the SJV, and moreover the activation energy, $E_{\mathrm{a}}$, derived from the fit is $76 \mathrm{~kJ} \mathrm{~mol}^{-1}$ is very similar to that found by Elsgaard et al. (2016) of $81 \mathrm{~kJ} \mathrm{~mol}^{-1}$. The correlation coefficient for the linear fits does not change significantly when the flight data from the two dates mentioned above are included ( $r^{2}$ of 0.54 instead of 0.58$)$.

\subsubsection{Surface latent heat flux}

Rearrangement of the water budget relationship Eq. (5), in a fashion similar to that of methane, leads to the ready estimation of surface latent heat fluxes for each campaign. The av-

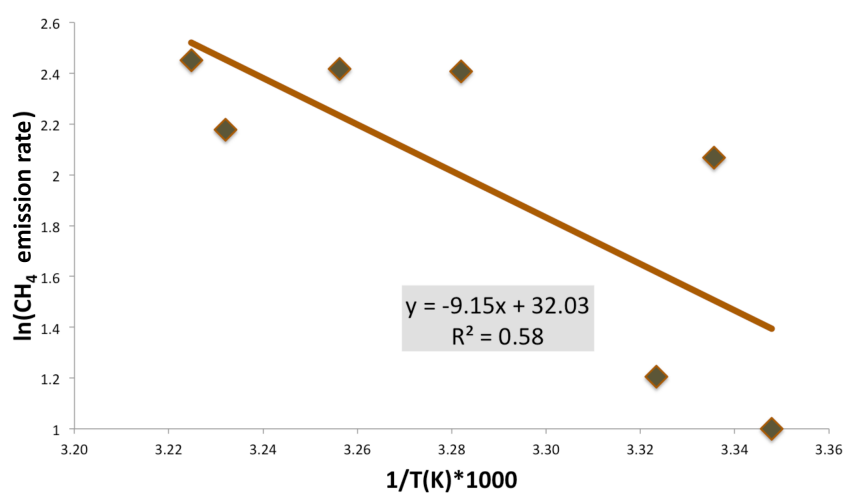

Figure 11. Arrhenius plot of the estimated methane emission rate from each flight and the average ABL temperature from the ArvinO3 study where methane emissions are believed to be dominated by agricultural sources.

erage for summer flights around Bakersfield was $284 \mathrm{~W} \mathrm{~m}^{-2}$ and for winter outside of Fresno it was $90 \mathrm{~W} \mathrm{~m}^{-2}$. Comparing these values to reference evapotranspiration estimated by the CIMIS network (515 and $160 \mathrm{~W} \mathrm{~m}^{-2}$, respectively), we find that both experiments predict virtually identical fractions, $55 \%$, occurring across the regions. This is likely the result of mixed land uses dominated by agriculture with interspersed fallow and actively growing plots. As expected the latent heat fluxes were observed to be lower in winter as the solar radiation is smaller and crop demand for water is reduced, but in both seasons it was found to be dramatically larger than the surface latent heat fluxes used in the NARR reanalysis data. This result, which most likely arises due to the lack of accurate irrigation information in the NARR land surface model, is significant because it is most likely the reason why the reanalysis data report boundary layers that are very much higher than observed, therefore this data should be used with caution by the community.

\section{Error analysis}

The estimated errors from each term in each budget equation are reported in Tables S1-S3 in the Supplement. All of the airborne data collected within the (time dependent) ABL are used to calculate temporal trends and horizontal gradient terms using a multiple linear regression. Each term's standard error was estimated from a residual taken as the difference between the predicted values from the regression and the actual values normalized by the square root of the number of data points. Omega values taken from NARR reanalysis were assumed to have an error of $\pm 0.05 \mathrm{~Pa} \mathrm{~s}^{-1}$ $\left(\sim 0.5 \mathrm{~cm} \mathrm{~s}^{-1}\right)$, which we took to be a fairly conservative estimate. Albrecht et al. (2016) utilized vertical velocity from ECMWF reanalysis data, originally as omega values, in the same inversion height budget (Eq. 2) and they equally arbitrarily estimate the error as $\pm 0.1 \mathrm{~cm} \mathrm{~s}^{-1}$, a factor of five 
smaller than ours. The errors are propagated through the budget equations, and in the case of Eq. (2) all the coefficients are unity so the variances simply add together. The overall uncertainties in the entrainment velocities average to about $1 \mathrm{~cm} \mathrm{~s}^{-1}$, which come from nearly equal parts uncertainty in the temporal trend, advection, and the reanalysis vertical velocities. We note that such uncertainty magnitudes are not uncommon for such a difficult, yet important, parameter to measure (Vilà-Guerau de Arellano et al., 2004; de Roode and Duynkerke, 1997; Bretherton et al., 1995; Wolfe et al., 2015.) For the ozone budget we estimate the errors in the $\mathrm{O}_{3}$ jump between ABL and FT by eye and these range from $\sim 10$ to $100 \%$ of the jump values. This is combined with the entrainment velocity error from each flight to derive the combined uncertainty of the entrainment flux. For the deposition velocity we estimate an uncertainty of about $0.25 \mathrm{~cm} \mathrm{~s}^{-1}$ based on a range of midday values reported in the literature for similar environments. We do not include uncertainty in the boundary-layer height because we expect it to be relatively small at $\sim 5 \%(\sim 50$ of $\sim 1000 \mathrm{~m}$. $)$ The resultant relative errors in the net ozone production amounts to only $\sim 15-40 \%$. It is difficult to discern exact uncertainties from other studies to compare. Pusede et al. (2014) do not make any mention of uncertainty in their reports of this rate, while Brune et al. (2016) show that their estimated ozone production rates are twice as large when using observed $\mathrm{HO}_{2}$ than with modeled values. Errors were taken from instrumental specifications when considering the error in mean quantities, like ozone or methane concentration, and mean wind (for the advection terms). The errors in our methane emissions estimates are comparable to the estimates themselves, primarily because the leading term that balances the surface emissions is the entrainment dilution. Nevertheless, we feel that over the course of many flights the mission averages take on greater significance (although we do not divide it by the square root of the number of flights.) Moreover, because the flight-to-flight variations appear to exhibit an Arrhenius dependence on temperature, we believe that the methane emissions reported here are meaningful.

\section{Conclusions}

In situ measurement via targeted aircraft campaigns can help us understand key factors in boundary-layer dynamics, including entrainment. It is propitious when it comes to probing complex mesoscale features, i.e., areas influenced by mountain-valley dynamics. A better understanding of entrainment is integral to understanding air quality on the ground, and it has potential applications in quantifying the significance of trans-boundary contributions to local air pollution. The simple yet novel scalar budgeting technique, based on focused airborne sampling of the ABL outlined here, is invaluable to boundary-layer studies and can help inform atmospheric chemistry studies. From our analysis of the inversion height budget, the boundary-layer height advection balances the mean upward vertical wind forced by orographic convergence at the southern end of the SJV. This balance permits the measurement of entrainment by simply measuring the change in ABL height throughout the daytime. The NOAA RASS sounders would suffice in this region to make regular measurements of entrainment, and analysis of data reported by Bianco et al. (2011) from 2008 shows bimodal peaks in entrainment in early spring (March) and late summer (August) at Lost Hills approximately $40 \mathrm{~km}$ northwest of Bakersfield (between the two target regions of this study.) Similar bimodal peaks in entrainment were found during spring and autumn for sites throughout California's Central Valley, and may be related to the proximity of the LTS minima in those transition seasons, but this needs further study.

Subsidence in complex topography is not very well understood, cannot be measured accurately, and is likely to be quite sizeable. Future studies should target a better understanding of the large-scale vertical velocities in the lower atmosphere to better elucidate the mixing and transport. One way this might be achieved is to deploy an airborne investigation to measure the surface heat fluxes and inversion strength and observe the growth rate and horizontal gradients of the valley boundary layers. By using Eq. (2), the subsidence rate could be measured indirectly given that the advection and time rate of change terms were observed accurately, in conjunction with using a simple mixed-layer dynamical model (e.g., CLASS: http://classmodel.github.io/) to estimate the entrainment rate.

Applying the entrainment results of the budgeting of $\mathrm{ABL}$ height to the other scalars then leads to significant insights into their sources and controlling variables. It was found that entrainment dilution and dry deposition of $\mathrm{O}_{3}$ are comparable in magnitude (but opposite in sign) to the observed time rate of change, which itself is only one-third of the net photochemical production during the $\mathrm{O}_{3}$ season in the BakersfieldArvin area. While advection of $\mathrm{O}_{3}$ into the town of Arvin is consistently observed to be negative (lower $\mathrm{O}_{3}$ air being brought in by the up-valley flow), a steady advection of high $\mathrm{NO}_{x}$ upstream seems to keep the in situ production elevated in the Arvin area. Moreover, a proxy for the $\mathrm{VOC}$ : $\mathrm{NO}_{x}$ ratio was used from the airborne methane and the surface air quality network $\mathrm{NO}_{x}$ to show that $\mathrm{O}_{3}$ production is $\mathrm{NO}_{x}$-limited in the southern SJV in summer and mid-SJV in the winter. The methane budgets revealed stronger sources in the SJV than those in the CALGEM database, with a greater disparity in the wintertime near Fresno, where there is a greater fraction of methane from petroleum-related sources. And finally the water vapor budget showed that the evapotranspiration in these regions is approximately $55 \%$ of their reference values (with respect to well-watered and groomed grass) according to the CIMIS network in both seasons. These evapotranspiration rates are much larger than contained in the NARR data set, which does not appear to include realistic irrigation in 
its land surface module, and this will be a source of significant overestimation of boundary-layer heights throughout the year in the Central Valley.

This study shows that aircraft-based ABL budgeting studies can help to constrain regional emission rates and photochemical production rates - both of which are poorly constrained in current models. Emission rates derived by these methods bypass a lot of the complex issues associated with inverse modeling because the scales are smaller (covering areas of $30-50 \mathrm{~km}$ linear scale), and do not rely on highly parameterized vertical mixing processes. Moreover, by measuring the specific terms in the ozone budget, detailed comparisons with photochemical models can uncover distinct weaknesses in our current models and discern whether the difficulties lie in dynamical (transport) or chemical aspects of the numerical efforts.

\section{Data availability}

The flight data can be obtained by contacting Ian C. Faloona of the University of California Davis (icfaloona@ucdavis.edu). The RASS boundary-layer height data was obtained by contacting Irina Djalalova of CIRES, University of Colorado and NOAA ESRL at 303-4976238, or Laura Bianco of CIRES, University of Colorado NOAA/ESRL/PSD (laura.bianco@noaa.gov). The CALGEM methane source inventory can be requested at http: //calgem.lbl.gov/prior_emission.html\# (Fisher, 2016). The North American Reanalysis (NARR) data can be found here http://www.esrl.noaa.gov/psd/data/gridded/data.narr.html (NOAA/OAR/ESRL, 2016).

\section{The Supplement related to this article is available online at doi:10.5194/acp-16-15433-2016-supplement.}

Acknowledgements. The ArvinO3 study was made possible by backing from the San Joaquin Valley Air Pollution Control District. We would especially like to thank David Lighthall, may he rest in peace, for his enthusiastic support, many fruitful discussions, and for his friendship. Flight time to participate in NASA's DISCOVER-AQ was provided by the Bay Area Air Quality Management District, and we thank the former's Jim Crawford and the latter's Saffet Tanrikulu for making it happen. We are very indebted to Irina Djalalova, Laura Bianco, and James Wilczak for providing us with their RASS boundary-layer height data from across the Central Valley. We further thank Doug Baer and his colleagues at Los Gatos Research for the generous loan of their $\mathrm{NO}_{2}$ spectrometer, and Marc Fischer for freely sharing his CALGEM methane source inventory. The reviews by three anonymous referees helped to improve the clarity of the manuscript, and we thank them for their efforts.
Edited by: M. Petters

Reviewed by: three anonymous referees

\section{References}

Albrecht, B., Fang, M., and Ghate, V.: Exploring Stratocumulus Cloud-Top Entrainment Processes and Parameterizations by Using Doppler Cloud Radar Observations, J. Atmos. Sci., 73, 729742, 2016.

Al-Saadi, J., Soja, A., Pierce, R. B., Szykman, J., Wiedinmyer, C., Emmons, L., Kondragunta, S., Zhang, X. Y., Kittaka, C., Schaack, T., and Bowman, K.: Intercomparison of near-real-time biomass burning emissions estimates constrained by satellite fire data, J. Appl. Remote Sens., 2, 021504, doi:10.1117/1.2948785, 2008.

Angevine, W. M.: Errors in mean vertical velocities measured by boundary layer wind profilers, J. Atmos. Ocean. Tech., 14, 565-569, doi:10.1175/15200426(1997)014<0565:Eimvvm>2.0.Co;2, 1997.

Baidar, S.: Combining Active and Passive Airborne Remote Sensing to Quantify $\mathrm{NO}_{2}$ and $\mathrm{O}_{x}$ Production near Bakersfield, CA, BJECC British Journal of Environment and Climate Change, 3, 566-586, 2013.

Ball, F. K.: Control of Inversion Height by Surface Heating, Q. J. Roy. Meteor. Soc., 86, 482-494, 1960.

Bandy, A., Faloona, I. C., Blomquist, B. W., Huebert, B. J., Clarke, A. D., Howell, S. G., Mauldin, R. L., Cantrell, C. A., Hudson, J. G., Heikes, B. G., Merrill, J. T., Wang, Y., O’Sullivan, D. W., Nadler, W., and Davis, D. D.: Pacific Atmospheric Sulfur Experiment (PASE): Dynamics and Chemistry of the South Pacific Tropical Trade Wind Regime, J. Atmos. Chem., 68, 5-25, 2011.

Bianco, L., Wilczak, J. M., and White A. B.: Convective Boundary Layer Depth Estimation from Wind Profilers: Statistical Comparison between an Automated Algorithm and Expert Estimations, J. Atmos. Ocean. Tech., 25, 1397-1413, 2008.

Bianco, L., Djalalova, I. V., King, C. W., and Wilczak, J. M.: Diurnal Evolution and Annual Variability of Boundary-Layer Height and Its Correlation to Other Meteorological Variables in California's Central Valley, Bound.-Lay. Meteorol., 140, 491-511, 2011.

Bretherton, C. S., Austin, P., and Siems, S. T.: Cloudiness and marine boundary-layer dynamics in the ASTEX Lagrangian experiments .2. Cloudiness, drizzle, surface fluxes, and entrainment, J. Atmos. Sci., 52, 2724-2735, doi:10.1175/15200469(1995)052<2724:cambld>2.0.co;2, 1995.

Brune, W. H., Baier, B. C., Thomas, J., Ren, X., Cohen, R. C., Pusede, S. E., Browne, E. C., Goldstein, A. H., Gentner, D. R., Keutsch, F. N., Thornton, J. A., Harrold, S., Lopez-Hilfiker, F. D., and Wennberg, P. O.: Ozone production chemistry in the presence of urban plumes, Faraday Discuss., 189, 169-189, doi:10.1039/c5fd00204d, 2016.

Chen, W. B., Kuze, H., Uchiyama, A., Suzuki, Y., and Takeuchi, N.: One-year observation of urban mixed layer characteristics at Tsukuba, Japan using a micro pulse lidar, Atmos. Environ., 35, 4273-4280, doi:10.1016/s1352-2310(01)00181-9, 2001.

Conley, S. A., Faloona, I., Miller, G. H., Lenschow, D. H., Blomquist, B., and Bandy, A.: Closing the dimethyl sulfide budget in the tropical marine boundary layer during the Pacific At- 
mospheric Sulfur Experiment, Atmos. Chem. Phys., 9, 87458756, doi:10.5194/acp-9-8745-2009, 2009.

Conley, S. A., Faloona, I. C., Lenschow, D. H., Campos, T., Heizer, C., Weinheimer, A., Cantrell, C. A., Mauldin, R. L., Hornbrook, R. S., Pollack, I., and Bandy, A.: A Complete Dynamical Ozone Budget Measured in the Tropical Marine Boundary Layer during PASE, J. Atmos. Chem., 68, 55-70, 2011.

Conley, S. A., Faloona, I. C., Lenschow, D. H., Karion, A., and Sweeney, C.: A Low-Cost System for Measuring Horizontal Winds from Single-Engine Aircraft, J. Atmos. Ocean. Tech., 31, 1312-320, 2014.

de Roode, S. R. and Duynkerke, P. G.: Observed Lagrangian transition of stratocumulus into cumulus during ASTEX: Mean state and turbulence structure, J. Atmos. Sci., 54, 2157-2173, doi:10.1175/1520-0469(1997)054<2157:oltosi>2.0.co;2, 1997.

Elsgaard, L., Olsen, A. B., and Petersen, S. O.: Temperature response of methane production in liquid manures and co-digestates, Sci. Total Environ., 539, 78-84, doi:10.1016/j.scitotenv.2015.07.145, 2016.

Faloona, I. C., Lenschow, D. H., Campos, T., Stevens, B., Van Zanten, M., Blomquist, B., Thornton, D., Bandy, A., and Gerber, H.: Observations of Entrainment in Eastern Pacific Marine Stratocumulus Using Three Conserved Scalars, J. Atmos. Sci., 62, 32683285, 2005.

Faloona, I. C., Conley, S. A., Blomquist, B., Clarke, A. D., Kapustin, V., Howell, S., Lenschow, D. H., and Bandy A. R.: Sulfur Dioxide in the Tropical Marine Boundary Layer: Dry Deposition and Heterogeneous Oxidation Observed during the Pacific Atmospheric Sulfur Experiment, J. Atmos. Chem., 63, 13-32, 2010.

Fisher, M.: California Greenhouse gas emissions measurement (CALGEM), Lawrence Berkeley National Laboratory, http: //calgem.lbl.gov/prior_emission.html\#, last access: February 2016.

Frenzel, C. W.: Diurnal wind variations in central California, J. Appl. Meteorol., 1, 405-412, 1962.

Gentner, D. R., Ford, T. B., Guha, A., Boulanger, K., Brioude, J., Angevine, W. M., de Gouw, J. A., Warneke, C., Gilman, J. B., Ryerson, T. B., Peischl, J., Meinardi, S., Blake, D. R., Atlas, E., Lonneman, W. A., Kleindienst, T. E., Beaver, M. R., Clair, J. M. St., Wennberg, P. O., VandenBoer, T. C., Markovic, M. Z., Murphy, J. G., Harley, R. A., and Goldstein, A. H.: Emissions of organic carbon and methane from petroleum and dairy operations in California's San Joaquin Valley, Atmos. Chem. Phys., 14, 4955-4978, doi:10.5194/acp-14-4955-2014, 2014.

Hays, T. P., Kinney, J. K., and Wheeler, N. J.: California surface wind climatology, California Air Resources Board Rep., Sacramento, USA, 1984.

Karl, T., Misztal, P. K., Jonsson, H. H., Shertz, S., Goldstein, A. H., and Guenther, A. B.: Airborne Flux Measurements of BVOCs above Californian Oak Forests: Experimental Investigation of Surface and Entrainment Fluxes, OH Densities, and Damköhler Numbers, J. Atmos. Sci., 70, 3277-3287, 2013.

Kawa, S. R. and Pearson Jr., R.: An observational study of stratocumulus entrainment and thermodynamics, J. Atmos. Sci., 46, 2649-2661, 1989a.

Kawa, S. R. and Pearson Jr., R.: Ozone budgets from the dynamics and chemistry of marine stratocumulus experiment, J. Geophys. Res., 94, 9809-9817, 1989b.
Korhonen, K., Giannakaki, E., Mielonen, T., Pfüller, A., Laakso, L., Vakkari, V., Baars, H., Engelmann, R., Beukes, J. P., Van Zyl, P. G., Ramandh, A., Ntsangwane, L., Josipovic, M., Tiitta, P., Fourie, G., Ngwana, I., Chiloane, K., and Komppula, M.: Atmospheric boundary layer top height in South Africa: measurements with lidar and radiosonde compared to three atmospheric models, Atmos. Chem. Phys., 14, 4263-4278, doi:10.5194/acp-14-42632014, 2014.

Kort, E. A., Frankenberg, C., Costigan, K. R., Lindenmaier, R., Dubey, M. K., and Wunch, D.: Four Corners: The Largest US Methane Anomaly Viewed from Space, Geophys. Res. Lett., 41, 6898-6903, 2014.

Lehning, M., Richner, H., Kok, G. L., and Neininger, B.: Vertical exchange and regional budgets of air pollutants over densely populated areas, Atmos. Environ., 32, 1353-1363, doi:10.1016/s1352-2310(97)00249-5, 1998.

Lenschow, D. H.: Airplane measurements of planetary boundary layer structure, J. Appl. Meteorol., 9, 874-884, 1970.

Lenschow, D. H., Pearson, R., and Stankov, B. B.: Estimating the Ozone Budget in the Boundary Layer by Use of Aircraft Measurements of Ozone Eddy Flux and Mean Concentration, J. Geophys. Res., 86, 7291-7297, doi:10.1029/JC086iC08p07291, 1981.

Lenschow, D. H., Paluch, I. R., Bandy, A. R., Thornton, D. C., Blake, D. R., and Simpson, I.: Use of a mixed-layer model to estimate dimethylsulfide flux and application to other trace gas fluxes, J. Geophys. Res.-Atmos., 104, 16275-16295, doi:10.1029/1998jd100090, 1999.

Lenschow, D. H., Savic-Jovcic, V., and Stevens, B.: Divergence and vorticity from aircraft air motion measurements, J. Atmos. Ocean. Tech., 24, 2062-2072, doi:10.1175/2007JTECHA940.1, 2007.

Lewis, J. R., Welton, E. J., Molod, A. M., and Joseph, E.: Improved boundary layer depth retrievals from MPLNET, J. Geophys. Res.-Atmos., 118, 9870-9879, doi:10.1002/jgrd.50570, 2013.

Li, Y. P., Smith, R. B., and Grubisic, V.: Using Surface Pressure Variations to Categorize Diurnal Valley Circulations: Experiments in Owens Valley, Mon. Weather Rev., 137, 1753-1769, doi:10.1175/2008mwr2495.1, 2009.

Macpherson, J. I., Desjardins, R. L., Schuepp, P. H., and Pearson, R.: Aircraft-Measured Ozone Deposition In The San-Joaquin Valley Of California, Atmos. Environ., 29, 3133-3145, 1995.

Miller, S. M., Wofsy, S. C., Michalak, A. M., Kort, E. A., Andrews, A. E., Biraud, S. C., Dlugokencky, E. J., Eluszkiewicz, J., Fischer, M. L., Janssens-Maenhout, G., Miller, B. R., Miller, J. B., Montzka, S. A., Nehrkorn, T., and Sweeney, C.: Anthropogenic emissions of methane in the United States, P. Natl. Acad. Sci. USA, 110, 20018-20022, doi:10.1073/pnas.1314392110, 2013.

Moore, G. E., Daly, C., Liu, M. K., and Huang, S. J.: Modeling Of Mountain-Valley Wind Fields In The Southern San-Joaquin Valley, California, J. Clim. Appl. Meteorol., 26, 1230-1242, 1987.

Nichols, S.: The dynamics of stratocumulus: Aircraft observations and comparisons with a mixed layer model, Q. J. Roy. Meteor. Soc., 110, 783-820, 1984.

NOAA/OAR/ESRL: NARR, PSD in Boulder, Colorado, http:// www.esrl.noaa.gov/psd/data/gridded/data.narr.html, last access: June 2016.

Padro, J.: Summary of ozone dry deposition velocity measurements and model estimates over vineyard, cotton, grass and 
deciduous forest in summer, Atmos. Environ., 30, 2363-2369, doi:10.1016/1352-2310(95)00352-5, 1996.

Pal, S. and Haeffelin, M.: Forcing mechanisms governing diurnal, seasonal, and interannual variability in the boundary layer depths: Five years of continuous lidar observations over a suburban site near Paris, J. Geophys. Res.-Atmos., 120, 11936-11956, doi:10.1002/2015JD023268, 2015.

Pio, C. A., Feliciano, M. S., Vermeulen, A. T., and Sousa, E. C.: Seasonal variability of ozone dry deposition under southern European climate conditions, in Portugal, Atmos. Environ., 34, 195205, doi:10.1016/S1352-2310(99)00276-9, 2000.

Pusede, S. E. and Cohen, R. C.: On the observed response of ozone to $\mathrm{NO}_{x}$ and VOC reactivity reductions in San Joaquin Valley California 1995-present, Atmos. Chem. Phys., 12, 8323-8339, doi:10.5194/acp-12-8323-2012, 2012.

Pusede, S. E., Gentner, D. R., Wooldridge, P. J., Browne, E. C., Rollins, A. W., Min, K.-E., Russell, A. R., Thomas, J., Zhang, L., Brune, W. H., Henry, S. B., DiGangi, J. P., Keutsch, F. N., Harrold, S. A., Thornton, J. A., Beaver, M. R., St. Clair, J. M., Wennberg, P. O., Sanders, J., Ren, X., VandenBoer, T. C., Markovic, M. Z., Guha, A., Weber, R., Goldstein, A. H., and Cohen, R. C.: On the temperature dependence of organic reactivity, nitrogen oxides, ozone production, and the impact of emission controls in San Joaquin Valley, California, Atmos. Chem. Phys., 14, 3373-3395, doi:10.5194/acp-14-3373-2014, 2014.

Rampanelli, G., Zardi, D., and Rotunno, R.: Mechanisms of upvalley winds, J. Atmos. Sci., 61, 3097-3111, doi:10.1175/jas3354.1, 2004.

Russell, A. R., Valin, L. C., Bucsela, E. J., Wenig, M. O., and Cohen, R. C.: Space-based Constraints on Spatial and Temporal Patterns of $\mathrm{NO}_{x}$ Emissions in California, 2005-2008, Environ. Sci. Technol., 44, 3608-3615, doi:10.1021/es903451j, 2010.

Schmidl, J. and Rotunno, R.: Mechanisms of Along-Valley Winds and Heat Exchange over Mountainous Terrain, J. Atmos. Sci., 67, 3033-3047, doi:10.1175/2010jas3473.1, 2010.

Schultz, H. B., Akesson, N. B., and Yates, W. E.: The delayed "sea breezes" in the Sacramento Valley and the resulting favorable conditions for application of pesticides, B. Am. Meteorol. Soc., 42, 679-687, 1961.

Schween, J. H., Hirsikko, A., Löhnert, U., and Crewell, S.: Mixinglayer height retrieval with ceilometer and Doppler lidar: from case studies to long-term assessment, Atmos. Meas. Tech., 7, 3685-3704, doi:10.5194/amt-7-3685-2014, 2014.
Tennekes, H.: A Model for the Dynamics of the Inversion Above a Convective Boundary Layer, J. Atmos. Sci., 30, 558-567, 1973.

van der Kamp, D. and McKendry, I.: Diurnal and Seasonal Trends in Convective Mixed-Layer Heights Estimated from Two Years of Continuous Ceilometer Observations in Vancouver, BC, Bound.Lay. Meteorol., 137, 459-475, doi:10.1007/s10546-010-9535-7, 2010.

Vilà-Guerau de Arellano, J., Gioli, B., Miglietta, F., Jonker, H. J. J., Baltink, H. K., Hutjes, R. W. A., and Holtslag, A. A. M.: Entrainment Process of Carbon Dioxide in the Atmospheric Boundary Layer, J. Geophys. Res. 109, D18110, doi:10.1029/2004JD004725, 2004.

Vilà-Guerau de Arellano, J., Patton, E. G., Karl, T., van den Dries, K., Barth, M. C., and Orlando, J. J.: The role of boundary layer dynamics on the diurnal evolution of isoprene and the hydroxyl radical over tropical forests, J. Geophys. Res., 116, D07304, doi:10.1029/2010JD014857, 2011.

Warner, J. and Telford J. W.: A check of aircraft measurements of vertical heat flow, J. Atmos. Sci., 22, 463-465, 1965.

Wolfe, G. M., Hanisco, T. F., Arkinson, H. L., Bui, T. P., Crounse, J. D., Dean-Day, J., Goldstein, A., Guenther, A., Hall, S. R., Huey, G., Jacob, D. J., Karl T., Kim, P. S., Liu, X., Marvin, M. R., Mikoviny, T., Misztal, P. K., Nguyen, T. B., Peischl, J., Pollack, I., Ryerson, T., St. Clair, J. M., Teng, A., Travis, K. R., Ullmann, K., Wennberg, P. O., and Wisthaler, A.: Quantifying Sources and Sinks of Reactive Gases in the Lower Atmosphere Using Airborne Flux Observations, Geophys. Res. Lett., 42, 8231-8240, 2015.

Wood, R. and Bretherton, C. S.: Boundary layer depth, entrainment, and decoupling in the cloud-capped subtropical and tropical marine boundary layer, J. Climate, 17, 3576-3588, 2004.

Zaremba, L. L. and Carroll, J. J.: Summer wind flow regimes over the Sacramento Valley, J. Appl. Meteorol., 38, 1463-1473, 1999.

Zhong, S., Whiteman, C. D., and Bian, X.: Diurnal Evolution of Three-Dimensional Wind and Temperature Structure in California's Central Valley, J. Appl. Meteorol., 43, 1679-699, 2004. 